\title{
Porphyrin-Gold Nanomaterial for Efficient Drug Delivery to Cancerous Cells
}

\author{
Kaushik Bera, ${ }^{\dagger, \S}$ Samarpan Maiti, ${ }^{\ddagger}{ }^{\ddagger}$ Mritunjoy Maity, ${ }^{\dagger}$ Chitra Mandal, ${ }^{*}, \oplus$ and Nakul C. Maiti ${ }^{*}{ }^{\dagger}$ (i) \\ ${ }^{\dagger}$ Structural Biology and Bioinformatics Division and ${ }^{\ddagger}$ Cancer Biology \& Inflammatory Disorder Division, CSIR-Indian Institute of \\ Chemical Biology, 4, Raja S.C. Mullick Road, Kolkata 700032, India
}

\section{Supporting Information}

\begin{abstract}
With an aim to overcome multidrug resistance (MDR), nontargeted delivery, and drug toxicity, we developed a new nanochemotherapeutic system with tetrasodium salt of meso-tetrakis(4-sulfonatophenyl)porphyrin (TPPS) armored on gold nanoparticles (TPPS-AuNPs). The nanocarrier is able to be selectively internalized within tumor cells than in normal cells followed by endocytosis and therefore delivers the antitumor drug doxorubicin (DOX) particularly to the nucleus of diseased cells. The embedment of TPPS on the gold nanosurface provides excellent stability and biocompatibility to the nanoparticles. Porphyrin interacts with the gold nanosurface through the coordination interaction between gold and pyrrolic nitrogen atoms of the porphyrin and forms a strong association complex. DOX-loaded nanocomposite (DOX@TPPS-AuNPs) demonstrated enhanced cellular uptake with significantly reduced drug efflux in MDR brain cancer cells, thereby increasing the retention time of the drug within tumor cells. It exhibited about 9 times greater potency for cellular apoptosis via triggered release commenced by acidic $\mathrm{pH}$. DOX has been successfully loaded on the porphyrin-modified gold nanosurface noncovalently with high encapsulation efficacy $(\sim 90 \%)$ and tightly associated under normal physiological conditions but capable of releasing $\sim 81 \%$ of drug in a low-pH environment. Subsequently, DOX-loaded TPPS-AuNPs exhibited higher inhibition of cellular metastasis, invasion, and angiogenesis, suggesting that TPPS-modified AuNPs could improve the therapeutic efficacy of the drug molecule. Unlike free DOX, drug-loaded TPPS-AuNPs did not show toxicity toward normal cells. Therefore, higher drug encapsulation efficacy with selective targeting potential and acidic-pH-mediated intracellular release of DOX at the nucleus make TPPS-AuNPs a "magic bullet" for implication in nanomedicine.
\end{abstract}

\section{INTRODUCTION}

Current cancer treatments are mainly based on radiation and chemotherapeutic agents, which have several side effects including severe damage to epithelial surfaces, infertility, swelling of soft tissues, and other side effects. ${ }^{1}$ Multidrug resistance (MDR) is another primary limitation to the success of chemotherapy. ${ }^{2}$ Furthermore, many effective drugs are hydrophobic or if soluble, it is difficult for them to reach their targets. ${ }^{3}$ The development of highly efficient therapeutics to reverse MDR is still a challenging task. In a similar tune, several antiviral drugs have showed low potency because many of these drug molecules fail to effectively cross the blood-brain barrier. Several reports suggested that nanoparticles (NPs), particularly from gold, could be a choice that has a strong potential to deliver a drug inside cancer cells. Nanosized gold particles possess distinctive shape and size and unique chemical properties that rendered them to be used as a drug delivery cargo. $^{4-6}$ To make them a better choice as a delivery system, modifications of the nanosurface are often made with ligands that preferentially bind to a specific receptor of the target cells. $^{7-9}$ Such modification enhanced the permeability and retention of drug molecules, which were then preferably localized to tumor sites with a high concentration level and thus enhanced the drug effect. Some of the modifications also enhanced the drug loading capacity, thereby reducing the large dose and the toxic effect of the drug molecules. ${ }^{10}$ Doxorubicin (DOX) is a common drug used in a wide range of cancers, and DOX-functionalized gold nanoparticles (AuNPs) exhibited significantly higher efficacy compared to that of free DOX in a biological environment. ${ }^{11-14}$ DOX loaded with poly(ethylene glycol) (PEG)-AuNPs could significantly overcome MDR in MCF-7/ADR breast cancer cells compared with free doxorubicin. ${ }^{15}$ Suarasan et al. showed that DOX-loaded gelatincoated AuNPs can be used as a nanochemotherapeutic system for the treatment of MCF-7 cells. ${ }^{16}$ Elbialy et al. demonstrated higher accumulation of drug with DOX-loaded magnetic AuNPs compared to that by passive targeting. ${ }^{17}$ Lee et al. prepared DOX-loaded oligonucleotide-conjugated gold nanoparticles as a promising in vivo drug delivery system for colorectal cancer. ${ }^{18}$ Dual activity including chemotherapy and

Received: March 6, 2018

Accepted: April 17, 2018

Published: April 26, 2018 
Scheme 1. Molecular Structure of Tetrasodium salt of meso-Tetrakis(4-sulfonatophenyl)porphyrin (TPPS) (A) and Doxorubicin (DOX) (B) Used in the Preparation of Complexes

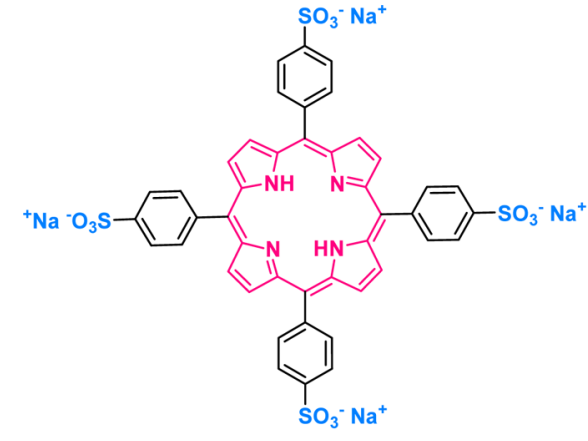

A<smiles>COc1cccc2c1C(=O)c1c(O)c3c(c(O)c1C2=O)[C@@](O)(C(=O)O)CC[C@H]3O[C@H]1C[C@H](N)[C@H](O)[C@H](C)O1</smiles>

B

Scheme 2. Schematic Representation of the Possible Mechanism of Formation of TPPS-Conjugated AuNPs and Subsequent Loading of DOX on Their Surface

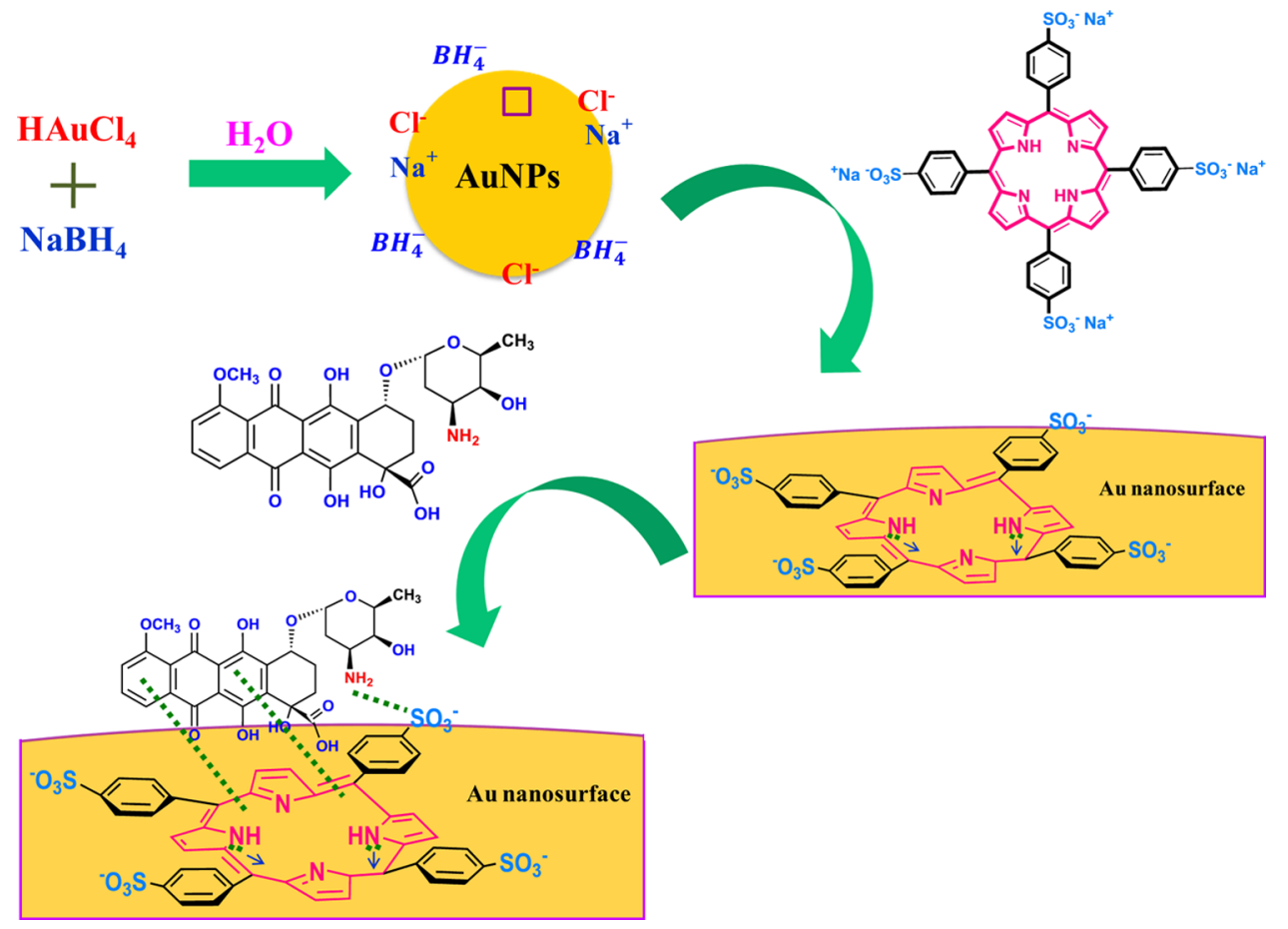

photothermal treatment using AuNPs coated with DOX-loaded fucoidan was also observed in eye tumors. ${ }^{19}$ In the current article, we developed tetrasodium salt of meso-tetrakis(4sulfonatophenyl)porphyrin-modified gold nanoparticles (TPPS-AuNPs) that efficiently delivered the loaded doxorubicin (DOX) molecule within the nucleus of tumor cells and thereby improved the therapeutic efficacy of the drug.

Porphyrins are highly conjugated aromatic molecules and show interesting spectroscopic and electronic properties. They have immense applications in the field of photodynamic and photothermal therapy. ${ }^{20-23}$ Porphyrin-stabilized gold nanoparticles using different porphyrins are reported. ${ }^{24,25}$ Structural analysis of the gold nanocomposite of thioester derivatives of tetrakis-5,10,15,20-(2-acetylthiophenyl)porphyrin showed that all four pyrrole nitrogen atoms of the porphyrin ring may participate in coordination with the gold nanosurface. ${ }^{26}$ The coupling of TPPS and magnetic nanoparticles possibly has wider applications in modern medicine. ${ }^{27}$ Porphyrins are reported to form hybrid nanostructures in the presence of different nanomaterials such as gold, graphene, tin oxide, etc. $^{28-30}$ Several porphyrin analogs were also conjugated with gold nanoparticles for better use in photodynamic therapy because of high triplet states and singlet oxygen quantum yield efficiency of porphyrin molecules. ${ }^{31-34}$

Here, we showed that the water-soluble tetrasodium salt of meso-tetrakis(4-sulphonatophenyl)porphyrin-modified gold nanoparticles (TPPS-AuNPs) has high efficiency to bind with doxorubicin and effectively delivered the loaded DOX within the nucleus of tumor cells. Our results established that TPPSAuNPs can significantly reduce the dose of DOX and thereby showed improved therapeutic efficacy toward killing of brain cancer cells, which is a challenging task because of the fast development and poor prognosis of this tumor.

\section{RESULTS AND DISCUSSION}

Porphyrin and its derivatives are often used in making important hybrid materials and assembly of gold nanoparticles. $^{26,29,35-39}$ It contains a flat and planar electron-rich 
A

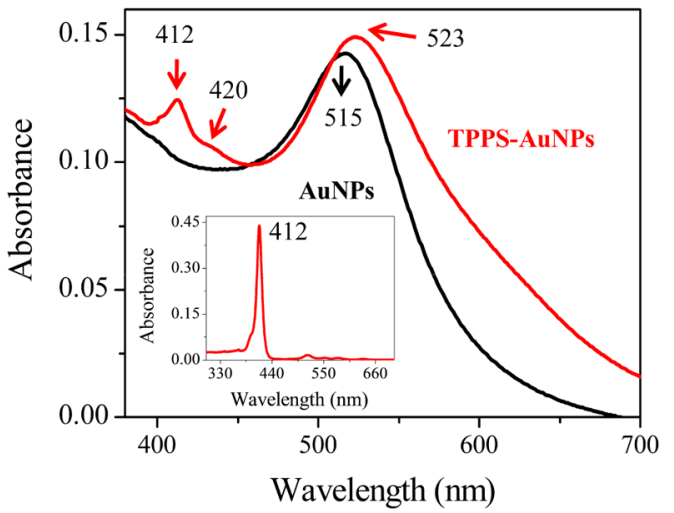

B

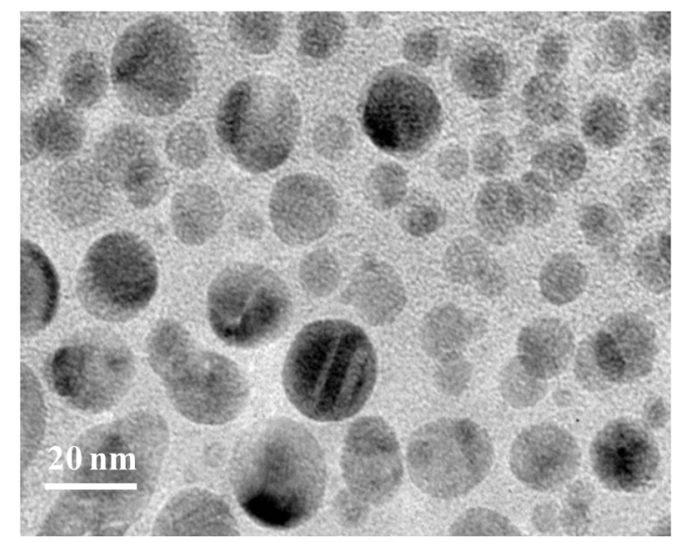

D

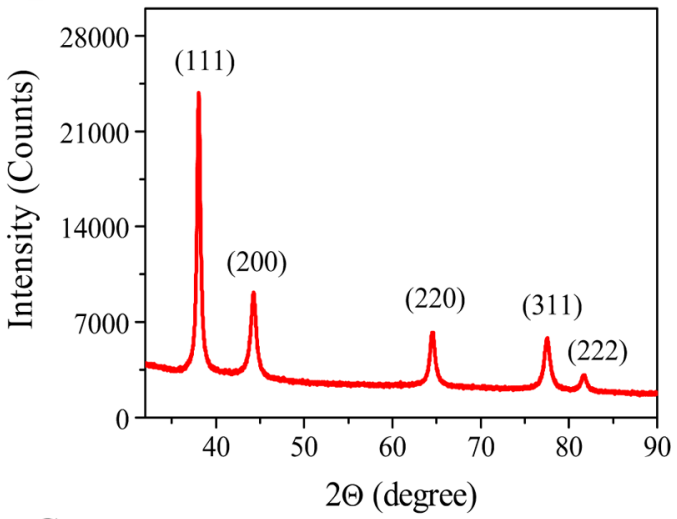

C

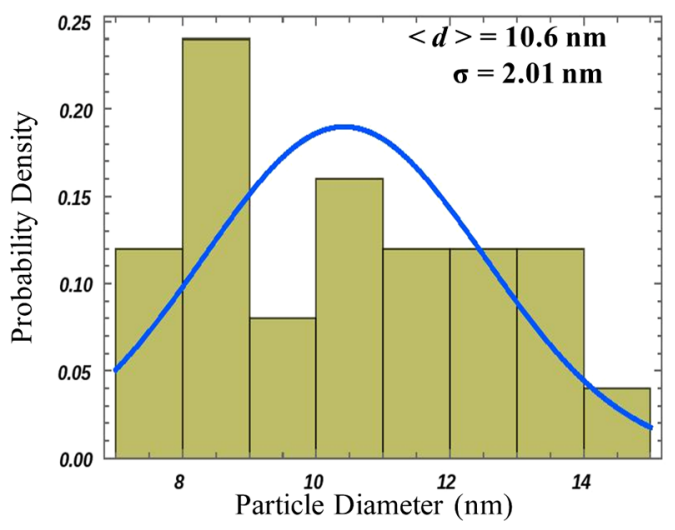

Figure 1. (A) UV-vis absorption spectra of TPPS-modified gold nanoparticles prepared at $\mathrm{pH} 9.0$ and dispersed in high-performance liquid chromatography (HPLC) water (red trace) along with bare AuNPs (black trace). The arrows at 412 and $420 \mathrm{~nm}$ are the Soret absorption peaks of porphyrin and those at 515 and $523 \mathrm{~nm}$ are for the SPR band of AuNPs. The inset figure shows the UV-vis absorption spectrum of free TPPS in the same aqueous basic medium. (B) High-resolution transmission electron microscopy (HRTEM) images of TPPS-AuNPs with a scale bar of $20 \mathrm{~nm}$. (C) Size distribution histogram and the fitted normal distribution curve of the nanoparticles. (D) Powder X-ray diffraction (XRD) pattern of TPPSAuNPs. The sample was drop-cast on a glass slide and dried at $60{ }^{\circ} \mathrm{C}$. The peaks are assigned based on JCPDS card no. 03-065-2870.

conjugated aromatic ring and facilitates interaction with metal nanosurfaces. Scheme 1 represents the molecular structure of TPPS and DOX. We utilized a simple reduction method to prepare bare gold nanoparticles (AuNPs) using aqueous solution of sodium borohydride $\left(\mathrm{NaBH}_{4}\right)$. Porphyrin-coated gold nanoparticles (TPPS-AuNPs) were subsequently prepared by incubating the freshly prepared AuNPs with TPPS via a continuous stirring method (Scheme 2, discussed in the Experimental Section). Figure 1A depicts the absorption behavior of a water suspension of freshly prepared TPPSAuNPs. The surface plasmon resonance (SPR) peak of TPPSAuNPs appeared at $523 \mathrm{~nm}$, and for the bare gold nanoparticles (AuNPs) in aqueous suspension, the peak was at $515 \mathrm{~nm}^{40}$ Thus, an $\sim 8 \mathrm{~nm}$ shift in the peak position was observed. The presence of porphyrin also resulted in the broadening of the plasmonic band, indicating a strong association of TPPS with the gold nanosurface. The Soret absorption peak in the UV-vis spectrum of free TPPS (aqueous solution, $\mathrm{pH} \sim 9.0$ ) appeared at $\sim 412 \mathrm{~nm}$ (Figure 1A, inset). ${ }^{41}$ The peak was quite broadened in TPPS-AuNPs, and a visible hump appeared at $\sim 420 \mathrm{~nm}$.

The SPR band is a key to envisage the size, shape, and interaction pattern of metal nanoparticles with other molecules. Several investigators observed a shift in the plasmonic band in nanocomposites because of coating with other molecules and in some cases because of agglomeration of the particles. Shaikh et al. observed a large shift $(525-570 \mathrm{~nm})$ in the AuNP plasmon band when treated it with porphyrin and purified it by passing through a specific column. ${ }^{37}$ However, agglomeration of the particles in the purification process could be the possible reason of the formation of bigger particles and the red shift in the SPR band. They also observed a small shift $(515-528 \mathrm{~nm})$ in the SPR band of the freshly prepared gold nanoparticles in the presence of porphyrin and purified it by a different method. Kanehara et al. prepared porphyrin-stabilized gold nanoparticles from citrate-protected gold nanomaterials, and only small changes in the SPR band were observed. ${ }^{26}$ They found that the Soret (from porphyrin ring) absorption peak shifted by 4-11 nm depending on the gap between the metal surface and the porphyrin ring. Ohyama et al. also developed a "lunarlander-like" porphyrin ligand that can stabilize the gold nanosurface with face-to-face parallel geometry. ${ }^{24}$ They observed a broad SPR band for the nanosurface and a bathochromic shift of $\sim 4 \mathrm{~nm}$ in the Soret absorption. The peak was broadened compared to that of free porphyrin in water. In our TPPS-armored gold nanoparticles, the Soret peak was broadened and a hump was observed at $\sim 420 \mathrm{~nm}$ compared to those of its monomer in solution $(\sim 412 \mathrm{~nm})$. The broadening and red shifting of the SPR band and the TPPS Soret absorption indicated that TPPS was involved in strong interaction with the gold nanosurface. ${ }^{37}$ 
Figure 1B shows the high-resolution transmission electron micrograph (HRTEM) of TPPS-AuNPs, which revealed that the particles were largely spherical in shape and were uniformly distributed. The transmission electron microscopy (TEM) image also confirmed low level of particle aggregation. Figure $1 \mathrm{C}$ shows the size distribution histogram of the nanoparticles and the fitted normal distribution curve. About 30 particles were randomly chosen from the enlarged TEM images to obtain the plot. The distribution analysis found that the average particle diameter was $\sim 10 \mathrm{~nm}$. The hydrodynamic size and $\zeta$ potential of the nanoparticles were also measured by dynamic light scattering (DLS) analysis in aqueous suspension. The distribution plots are shown in Figures S1 and S2. The average hydrodynamic diameter was $\sim 10 \mathrm{~nm}$. The measured surface potential of TPPS-AuNPs was $\sim-41 \mathrm{mV}$, whereas for bare AuNPs, it was $\sim-19 \mathrm{mV}$. The significant increase in the negative $\zeta$-potential value was due to surface modification caused by negatively charged sulphonated groups of TPPS.

The X-ray diffraction (XRD) pattern was also used to determine the crystalline nature of the synthesized particles. Figure 1D shows the powder X-ray diffraction pattern of TPPSAuNPs in the $2 \theta$ range $32-90^{\circ}$. It exhibited intense peaks at $\sim 38.10,44.30,64.50,77.60$, and 81.70 that correspond to diffraction from (111), (200), (220), (311), and (222) crystal planes, indicating that the synthesized gold nanoparticles were in the form of a face-centered cubic lattice in its solid state. The peaks were assigned using standard literature data based on JCPDS card no. 03-065-2870. The XRD peak patterns suggested nanocrystaline nature of the particles with $\mathrm{Fm} 3 \mathrm{~m}$ symmetry.

Isothermal titration calorimetry (ITC) is a sensitive technique that provides several thermodynmical parameters pertinent to binding of small molecules to the nanosurface and other macromolecular systems. It measures parameters such as the binding constant $\left(K_{\mathrm{a}}\right)$, change of Gibbs free energy $\left(\Delta G^{\circ}\right)$, and entropy change $\left(\Delta S^{\circ}\right)$ for the association processes. Figure $2 \mathrm{~A}$ shows the calorimetric profile of TPPS interaction with AuNPs at $25{ }^{\circ} \mathrm{C}$. The top panel shows the change in heat as a function of time for successive injection of TPPS. The heats of dilution obtained from control experiments of injecting identical amounts of the TPPS solution into the aqueous medium alone were subtracted to get corrected values of heat (shown at the top portion of the upper panels, curve). The lower panel shows the corrected integrated heats (black squares) plotted against the molar ratio of the association of TPPS with the gold nanoparticles, and the data were fitted to a single-site binding model. The calculated binding constant, standard molar enthalpy change, entropy contribution, and standard molar Gibbs energy change were $3.13 \times 10^{5} \mathrm{M}^{-1}$, $-11.22 \mathrm{kcal} / \mathrm{mol},-12.5 \mathrm{cal} / \mathrm{mol} \mathrm{deg}$, and $-7.5 \mathrm{kcal} / \mathrm{mol}$, respectively. The negative enthalpy and negative entropy values suggested the presence of possible electrostatic interactions between porphyrin and the metal nanosurface. The binding constant was similar to that for the binding of nonfunctional porphyrin to the gold nanosurface, as investigated by Shaikh et al., and for the interaction of TPPS to magnetic iron oxide nanoparticles and other nanosystems. ${ }^{27,37,42-44}$ It is likely that porphyrin got adsorbed on the AuNP surfaces through the coordination interaction between gold and pyrrolic nitrogen atoms of the porphyrin ring and formed a strong association complex.

Fourier transform infrared (FT-IR) analysis also suggested ample interaction of the metal surfaces with the porphyrin

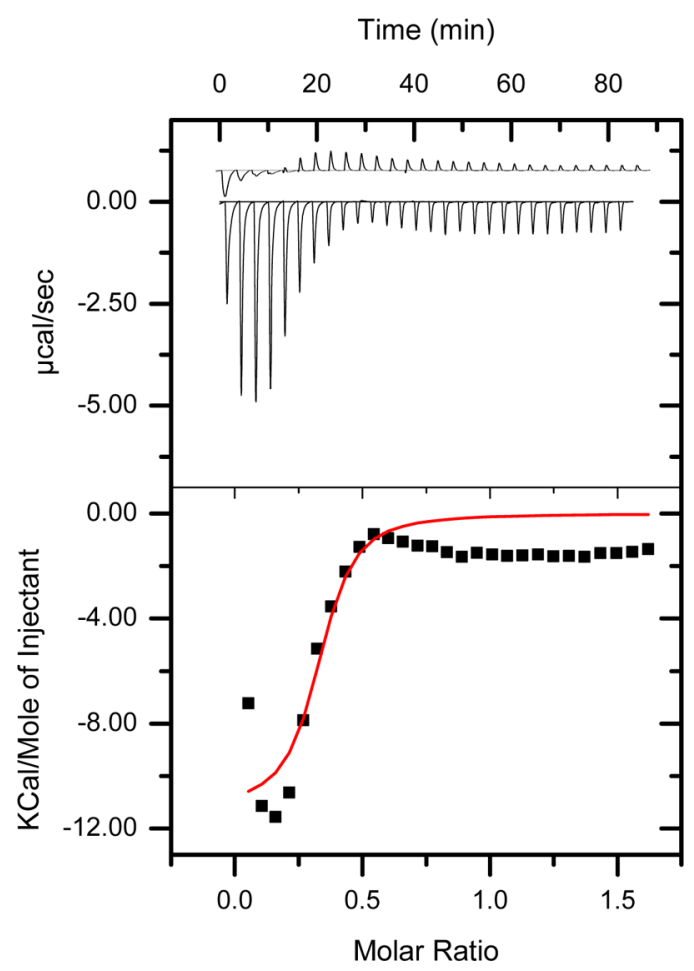

Figure 2. ITC profile for the binding of TPPS to AuNPs. The top panel presents raw heat effects for the titration of AuNP suspension with $1.8 \mathrm{mM}$ TPPS at $25{ }^{\circ} \mathrm{C}$ in aqueous basic medium $(\mathrm{pH} \sim 9.0)$. The bottom panel shows the integrated heat effects after correction of heat of dilution against the molar ratio of AuNPs to TPPS.

molecules. Figure S3 shows the FT-IR spectra of TPPS and TPPS-AuNPs. Some of the prominent FT-IR bands of TPPS appeared at 639, 738, 804, 1009, 1039, 1125, 1190, 1221 (shoulder), and $1395 \mathrm{~cm}^{-1}$. The bands were assigned based on the available literature. ${ }^{6,45,46}$ TPPS contains a $\pi$-conjugated porphyrin ring and four negatively charged sulphonated groups $\left(\mathrm{SO}_{3}^{-}\right)$connected to the phenyl moiety of the molecule. Many of the observed bands were linked to the phenyl moiety of the molecule. ${ }^{46,47}$ The bands at 1221 and $1190 \mathrm{~cm}^{-1}$ could be assigned to the vibrations of $\mathrm{SO}_{3}^{-}$groups of TPPS. Most of the vibration bands of TPPS also appeared in TPPS-AuNPs, however, with weak signals. The bands for the $\mathrm{SO}_{3}^{-}$groups were also present in the TPPS-AuNPs and shifted slightly. This indicated porphyrin interaction with the metal nanosurface. The bands at 1470,1009 , and $804 \mathrm{~cm}^{-1}$ were linked to the vibrations of bonds connected to ring nitrogens, and associated bond vibrations were more affected and some changes in the frequency position were observed. The ring nitrogen atoms might be involved in coordination with the metal nanosurface and perturbed the ring vibrations to a certain extent, causing changes in some of these vibrational frequencies. ${ }^{46}$

We tested the stability of TPPS-AuNPs under high salt concentration conditions. Figure 3 shows the optical absorption spectra of TPPS-AuNPs in several ionic buffers at high ionic strength $(\sim 100 \mathrm{mM})$ after incubating for $30 \mathrm{~min}$ at $37^{\circ} \mathrm{C}$. The SPR band remained at $523 \mathrm{~nm}$, and no significant change was observed. The porphyrin Soret absorption peak was also found to be less affected. These two observations suggest an excellent colloidal stability of the nanoparticles. A charged nanosurface is usually prepared through surface coating with specific molecules. The charge over the nanoparticle surface creates a potential difference $(\zeta$ potential) and stabilizes the colloidal 


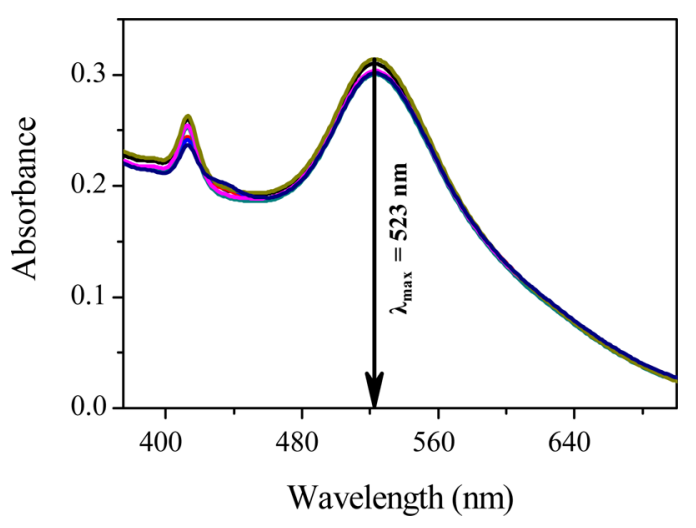

Figure 3. UV-visible absorption spectra of the TPPS-AuNPs in different ionic buffer mediums (100 mM), namely, $\mathrm{N}-(2$ hydroxyethyl)piperazine- $N^{\prime}$-ethanesulfonic acid (HEPES) (black), $\mathrm{KCl}$ (red), $\mathrm{NaCl}$ (blue), phosphate-buffered saline (PBS) (dark cyan), phosphate (magenta), Tris- $\mathrm{HCl}$ (dark yellow), and water (navy) under normal physiological conditions $\left(\mathrm{pH} \sim 7.4,37^{\circ} \mathrm{C}\right.$ ).

nanoparticle suspension in solutions by repulsive electrostatic interactions. However, electrostatically stabilized nanoparticles are prone to aggregation in different chemical or biological media because of neutralization of the surface charge by ionic species present in the media. The prolonged colloidal stability experienced by TPPS-AuNPs in different media (Figure 3) may be due to the presence of stable TPPS embedment. Highly hydrophilic TPPS coatings have been shown to resist ion adsorption and also provide steric hindrance, thus preventing aggregation and coagulation to form bigger particles.

Porphyrin molecules can form stable molecular junctions, and addition of anchoring groups to the porphyrin backbone increases the stability of the junctions. ${ }^{48}$ It was observed that porphyrin with four amino groups binds strongly to AuNPs compared with porphyrin having less number of/no functional amino groups. With no functional amino groups, the porphyrin fluorescence intensity is quenched because of the standard faceon and face-off interactions of porphyrin with gold nanoparticles. Time-resolved fluorescence measurements indicated that the quenching of the fluorescence of porphyrin by AuNPs is of static type. ${ }^{37}$ Furthermore, it was established that the thiol functional groups have a higher affinity to the gold surface and showed strong binding to gold nanoparticles. ${ }^{49}$ Porphyrins with diamino groups and thiols show similar binding constants. Some groups studied the formation of $\mathrm{Au}$ and tetrapyridyl porphyrin complexes and suggested that $\mathrm{Au}$ atoms and small $\mathrm{Au}$ clusters can form dative bonds with the lone electron pair on a nitrogen atom; hence, the Au clusters are likely to bond to one of the pyridyl nitrogen atoms. ${ }^{50-52}$ Bhaumik et al. developed porphyrin-gold nanoconjugates as biocompatible photosensitizers and showed that the porphyrin with a carboxyl tether was successfully attached to the surface of the bioinspired metal nanoparticles (rich in $-\mathrm{OH}$ group) via covalent ester bond formation. ${ }^{53} \mathrm{Nada}$ et al. reported that $\pi$-conjugated phthalocyanine rings can serve as stabilizing ligands for gold nanoparticles through van der Waals interaction between parallel-adsorbed phthalocyanine ligands and the gold nanoparticle surface. ${ }^{54}$ Evdokimova et al. found that porphyrin with four bromine groups has a stronger affinity for the surfaces of gold nanoparticles than that of porphyrin without functional groups. ${ }^{55}$ Zhang et al. suggested that porphyrin monomers are first adsorbed on the gold nanosurfaces through the coordination interaction between gold and pyrrolic nitrogen atoms, followed by the formation of linear or necklace chain assemblies of the gold nanospheres via the $\pi-\pi$ stacking interaction between porphyrin monomers. ${ }^{35}$ Kanehara et al. showed that all of the ring nitrogen atoms of porphyrin are involved in binding to the nanosurface and aligned the porphyrin rings quite parallel to the gold nanosurface. ${ }^{26}$ The additional study established a very close face-on configuration that may generate a strong coupling between the $\pi$ orbital of the porphyrin ring and the $6 \mathrm{~s}$ orbital of gold. ${ }^{56}$

TPPS, used in our investigation, contained no sulfhydryl or $-\mathrm{NH}_{2}$ functional groups that could easily bind to the nanosurfaces. However, it contained a highly electron rich $\pi$ conjugated macrocyclic ring with two pyrrolic nitrogen $(-\mathrm{NH})$ atoms. The four sulphonated groups render the porphyrin molecule water-soluble but not stably functionalizing the AuNPs. However, pyrrolic nitrogen atoms have strong propensities to be involved in coordination with the metal surface. $^{27}$ It could be a strong association complex. ITC measurements established the binding/association constant for binding of TPPS to gold nanoparticles to be about $3 \times 10^{5}$ $\mathrm{M}^{-1}$. The adherence of TPPS to the nanosurface was further confirmed by the $\zeta$ potential measurement of both AuNPs and TPPS-AuNPs. A significant increase in the negative $\zeta$ potential value (from $-19 \mathrm{mV}$ of AuNPs to $-41 \mathrm{mV}$ of TPPS-AuNPs) could be attributed to the presence of TPPS ( $\mathrm{SO}_{3}^{-}$groups) on the gold nanosurface. FT-IR investigation (Figure S3) also showed the presence of TPPS on the gold nanosurface. This investigation also showed that some of the vibration bands are associated particularly with the macrocyclic ring (that contains nitrogen atoms) of the molecule affected, and not much difference was observed in the vibration of sulphonated groups. We further performed dialysis of the nanocomposite for 2 days in aqueous medium ( $\mathrm{pH} \sim 7.0)$ and observed that the porphyrin Soret absorption peak remained at $\sim 412 \mathrm{~nm}$; however, the peak was broadened. Steady-state fluorescence investigation (not shown) also suggested very strong binding of TPPS molecules to the nanoparticles. Upon repeated washing, some loss of porphyrin from the nanosurface was possible that could cause agglomeration of the nanostructures. ${ }^{37}$

The efficient delivery and release of a drug molecule to a targeted cell are a crucial challenge to improve therapies for a range of human diseases. We have selected tetrasodium salt of meso-tetrakis(4-sulfonatophenyl)porphyrin (TPPS) to modify the gold nanosurface. Its unique conductivity properties due to the conjugated $\pi$-system, structural flexibility, and several possible architectural modifications make it attractive for use in nanocomposites and the modulation of conductive properties of gold nanoparticles. TPPS is water-soluble. In vivo tumor localization potential of the porphyrin was found to be reasonably high. Furthermore, it has four $-\mathrm{SO}_{3}^{-}$groups that may interact with $-\mathrm{NH}_{2}$ groups of $\mathrm{DOX}$ through hydrogen bonding. These hydrogen bonds are very sensitive to $\mathrm{pH}$. In an acidic environment (cancer cells), the hydrogen bonding interactions become weak, resulting in the release of DOX from the nanosurface and thus making it available to kill the cells effectively. Here, we used a commonly used clinically approved anticancer drug (DOX) as a model system and embedded it on TPPS-AuNPs to make a ternary nanochemotherapeutic system, DOX@TPPS-AuNPs (Scheme 2). Loading of DOX was monitored by UV-vis spectroscopy, $\zeta$ potential, DLS, TEM, and fluorescence measurements. Figure 4A shows the UV-vis spectra associated with the SPR band of 
A

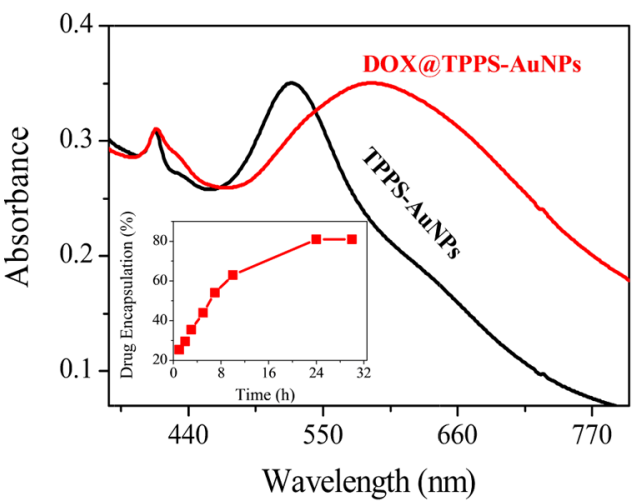

C

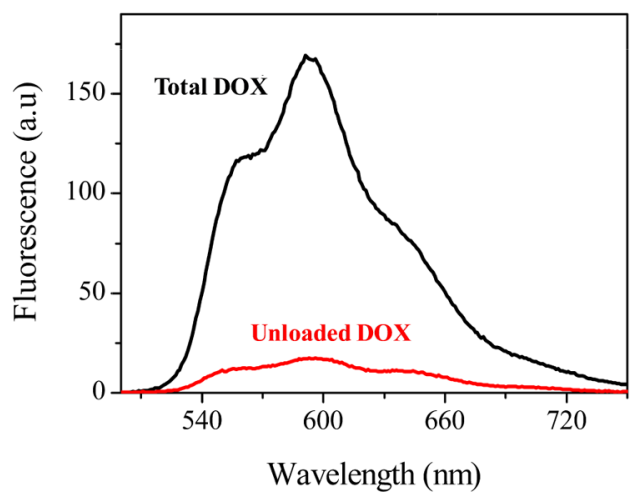

B

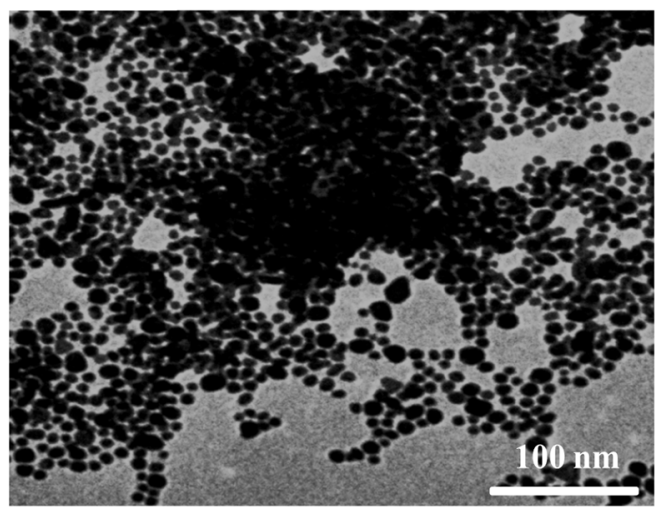

D

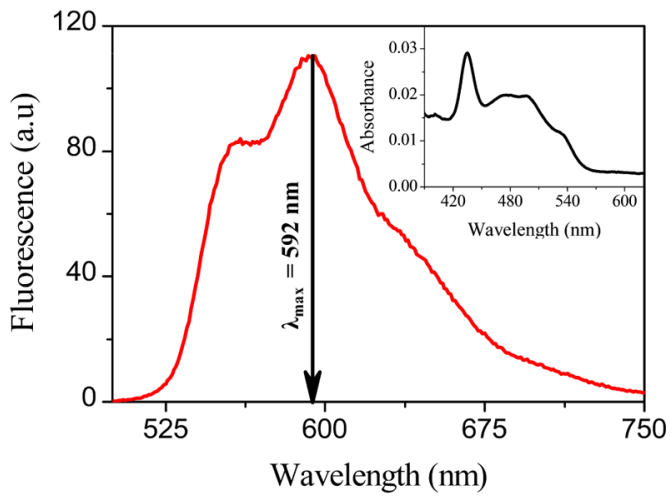

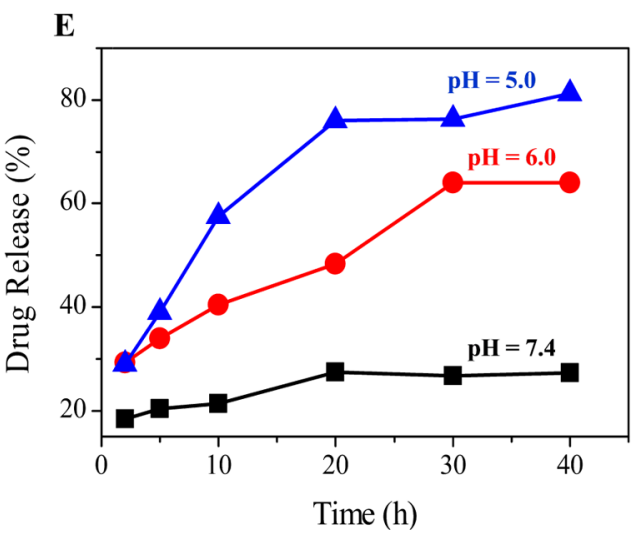

Figure 4. (A) Optical absorption spectra of TPPS-AuNPs and DOX@TPPS-AuNPs in water. The inset shows the encapsulation efficiency (EE) of DOX as a function of time on the surface of TPPS-AuNPs in aqueous medium at $\mathrm{pH} \sim$ 7.0. (B) TEM micrograph of TPPS-AuNPs loaded with doxorubicin (scale bar $100 \mathrm{~nm})$. (C) Fluorescence spectrum of DOX $(30 \mu \mathrm{M})$ in water (black trace) and fluorescence spectrum of the supernatant obtained upon adding TPPS-AuNPs to the DOX solution followed by filtration (red trace with reduced intensity). (D) Fluorescence spectrum of DOX released from the TPPS-AuNPs nanosurface after incubating DOX@TPPS-AuNPs at $\mathrm{pH}=5.0$ (citrate buffer) at $37^{\circ} \mathrm{C}$ for $40 \mathrm{~h}$. The inset shows the corresponding UV-vis spectrum. (E) Release of DOX from DOX@TPPS-AuNPs at $37^{\circ} \mathrm{C}$ incubated under three different solution conditions ( $\mathrm{pHs}$ varies) with time. The calculations of encapsulation efficiency and release \% are explained in the Materials and Methods section.

DOX-loaded and free TPPS-AuNPs. The inset in the figure shows the time-dependent doping of DOX on the porphyrincoated gold nanosurface. We found that after $1 \mathrm{~h}$ incubation of DOX with TPPS-AuNPs at $\mathrm{pH} 7.0, \sim 60 \%$ of DOX was entrapped. It increases slowly thereafter and reached a plateau, upto $\sim 90 \%$ encapsulation, at $24 \mathrm{~h}$. However, AuNPs entrapped only $\sim 25 \%$ of DOX for $1 \mathrm{~h}$ of incubation (Figure S4). The weight ratio of DOX to AuNPs/TPPS-AuNPs was 1:7. The reason of enhanced encapsulation by TPPS-AuNPs could be the favorable interactions between $-\mathrm{SO}_{3}^{-}$groups of TPPS on the gold nanosurface and $-\mathrm{NH}_{2}$ groups of $\mathrm{DOX}$. The binding interaction between the two groups was highly possible, and it was reported earlier. ${ }^{45}$ Upon DOX loading, the size of the nanoparticles increased, as confirmed by the large bathochromic shift of the SPR band from 523 to $584 \mathrm{~nm}$ (Figure 4A). The TEM micrograph also confirms the increased particle size upon DOX loading (Figure 4B). Figure 4C illustrates the usual fluorescence emission spectrum of DOX $(30 \mu \mathrm{M})$ in water. On addition of TPPS-AuNPs to the solution, mainly the bright fluorescence of DOX was substantially quenched, and it strongly suggested the encapsulation of DOX on TPPS-AuNPs. Thus, a novel ternary complex (DOX@TPPS-AUNPs) was 
formed. $\zeta$ potential and DLS measurements further supported the fact that DOX was sufficiently loaded in TPPS-AuNPs (Figure S5). The $\zeta$ potential value of TPPS-AuNPs was -41.1 $\mathrm{mV}$, and it was increased to $-34.3 \mathrm{mV}$ for DOX-loaded TPPSAuNPs. The hydrodynamic diameter also increased from 10 to $26 \mathrm{~nm}$ after DOX loading.

The flat porphyrin ring can possibly cradle and facilitate the incorporation of doxorubicin in the porphyrin-gold nanocomposite. Interactions (electrostatic and $\mathrm{H}$-bonding) among the polar and ionic groups $\left(\mathrm{SO}_{3}^{-}\right)$of TPPS and $-\mathrm{NH}_{2}$ groups of DOX or $\pi-\pi$ staking between the conjugated structure of the TPPS moiety and DOX could provide ample stabilization in the binding processes (Scheme 3). ${ }^{57}$ This kind of interaction

Scheme 3. Schematic Representation of Electrostatic Interaction and Hydrogen Bonding between Adsorbed TPPS and Adsorbed DOX Molecules on AuNP Surfaces ${ }^{a}$

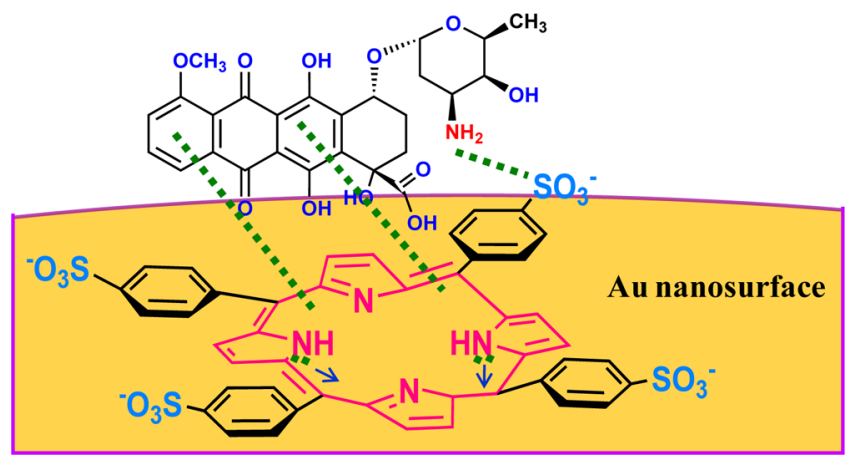

${ }^{a}$ TPPS molecules attached on the AuNP surface through coordination interaction.

was already observed between DOX and graphene oxide (containing electron-rich $\pi$-orbital substituted with the $\mathrm{CO}_{2}^{-}$ group). ${ }^{58,59}$ Therefore, DOX was noncovalently loaded on TPPS-AuNPs and the electrostatic/hydrogen bonding interaction was the major force in the association processes. The $\zeta$ potential of TPPS-AuNPs was $-41.1 \mathrm{mV}$ at neutral $\mathrm{pH}(\mathrm{pH}=$ 7.4), AuNPs being covered with the anionic TPPS porphyrin. The $\zeta$ potential of DOX-loaded TPPS-AuNPs was $-34.3 \mathrm{mV}$. The decrease in the $\zeta$ potential is attributed to the charge neutralization of suphonated groups. This also justified a large quenching of fluorescence of DOX (Figure 4C) in DOX@ TPPS-AuNPs, and both the facts supported the formation of a strong and stable ternary complex.

For efficient drug delivery, the biocompatibility of drug nanocarriers and controlled release of the drug at the pathological site are essential and important requirements. As we showed above, the DOX@TPPS-AuNP complex was formed by the adsorption of DOX on the surface of TPPSAuNP and the bonding was very strong at neutral $\mathrm{pH}$ and caused inefficient release. ${ }^{58}$ Once DOX was loaded, its fluorescence signal significantly quenched. However, when the DOX@TPPS-AuNPs system was dispersed in acidic buffers, the chances of pyrrolic nitrogen $(-\mathrm{NH})$ protonation increased and the $-\mathrm{NH}_{2}$ group $\left(\mathrm{p} K_{\mathrm{a}} \sim 7.2\right)$ of DOX also got protonated. This caused instability in the binding interaction of porphyrin/DOX with the metal nanosurface and resulted in the release of both DOX and porphyrin molecules from the metallic surface. The absorption spectrum (Figure 4D, inset) shows the Soret absorption peak of diprotonated porphyrin at $433 \mathrm{~nm}$ under acidic conditions $(\mathrm{pH} \sim 5.0) .^{60}$ However, the spectrum was dominated with the DOX absorption band.

To measure the pH-triggered uncapping efficiency of DOX@ TPPS-AuNPs nanoparticles in greater detail, the drug release experiments were performed by varying the $\mathrm{pH}$ of the solutions. A small amount of DOX@TPPS-AuNPs was incubated with different buffers of varying $\mathrm{pHs}$ and maintained at $37^{\circ} \mathrm{C}$ under gentle shaking. The amount of DOX released at different time intervals was measured based on the absorbance of the released DOX in the medium. Absorbance at $480 \mathrm{~nm}$ was recorded and plotted as a function of time to generate a release profile. Figure 4D shows the fluorescence emission spectrum of released DOX from the TPPS-AuNP surface after incubating the solution for $40 \mathrm{~h}$ at $\mathrm{pH} 5.0$ and at $37^{\circ} \mathrm{C}$. It showed strong fluorescence emission at $592 \mathrm{~nm}$, which is a characteristic emission wavelength of DOX. This observation also suggested that the molecular structure of DOX remained intact upon binding and subsequent release from TPPS-AuNPs and thus it can be available in the tumor environment (acidic $\mathrm{pH}$ ) to act effectively. A pH-dependent DOX release profile has been shown in Figure 4E. This shows much less ( 25\%) DOX releases after $40 \mathrm{~h}$ under normal physiological conditions $(\mathrm{pH}$ 7.4 and $37{ }^{\circ} \mathrm{C}$ ). At the end of $40 \mathrm{~h}$, the amount of DOX released was $\sim 64 \%$ at $\mathrm{pH} 6, \sim 81 \%$ at $\mathrm{pH} 5$ at $37{ }^{\circ} \mathrm{C}$. Thus, it was found that most of the DOX remained in the composite for a considerable length of time in the plasma under physiological conditions ( $\mathrm{pH} 7.4$ ). Hence, a reduction in the release of DOX to the normal tissue was observed as the $\mathrm{pH}$ of body fluids is around $\mathrm{pH}$ 7.4. The release of DOX was linked to the $\mathrm{pH}$ of the microenvironment surrounding the nanocomposite and the protonation of both the ring nitrogen of TPPS and the $-\mathrm{NH}_{2}$ group of DOX. Protonation of the ring nitrogens causes instability in the binding interaction of porphyrin with the metal nanosurface and protonation of the $-\mathrm{NH}_{2}$ group causes instability to the electrostatic interaction between the TPPS and DOX. Chances of protonation of the pyrrolic nitrogens/$\mathrm{NH}_{2}$ of DOX increase with a decrease in the $\mathrm{pH}$ of the solution. The absorption spectrum at $\mathrm{pH} \sim 5.0$ (Figure $4 \mathrm{D}$, inset) shows the strong Soret absorption peak of diprotonated porphyrin at $433 \mathrm{~nm}$. However, the $\mathrm{p} K_{\mathrm{a}}$ of porphyrin pyrrolic nitrogen is $\sim 4.9$ and that of the cellular environment in cancerous cells is $\sim 6.0$. The change of $\mathrm{pH}$ from 7.4 to 6.0 may not result in a drastic change what we observed at $\mathrm{pH} \sim 5.0$; however, the medium is sufficiently acidic to weaken the binding interaction of TPPS with AuNPs. At $\mathrm{pH}$ 6.0, however, the $-\mathrm{NH}_{2}$ groups of DOX $\left(\mathrm{p} K_{\mathrm{a}} \sim 7.2\right)$ may be protonated to a greater extent. It could make the interaction of DOX and TPPS on the nanosurface very unstable. We found that DOX was released more at acidic $\mathrm{pH}$ (Figure $4 \mathrm{E}$ ). Taken together, the $\mathrm{pH}$-dependent release may help improve the efficiency of DOX@TPPS-AuNPs as an efficient delivery system, where the normal cells are less affected.

Multidrug resistances resulting from the expression of the mdr-1 and mrp-1 gene products are the major barriers for the successful chemotherapy in cancer. ${ }^{61-63}$ Overexpression of MDR gene-encoded P-glycoproteins and MDR-associated proteins is responsible for quick drug efflux from cancer cells, which reduces the effective drug concentrations within the cells and thus decreases its sensitivity. LN229 cells express both mdr1 and mrpl and also higher P-glycoprotein levels. ${ }^{64}$ We examined if TPPS-AuNPs could overcome the lower drug accumulation and retention in LN229 cells. Accordingly, LN229 cells were incubated with free DOX and DOX@ 


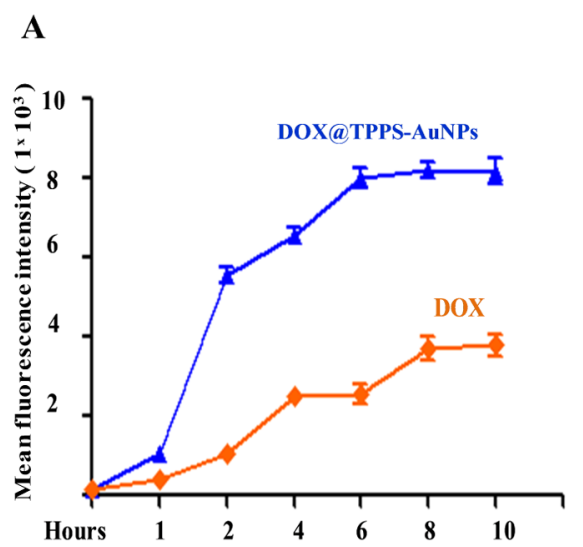

D

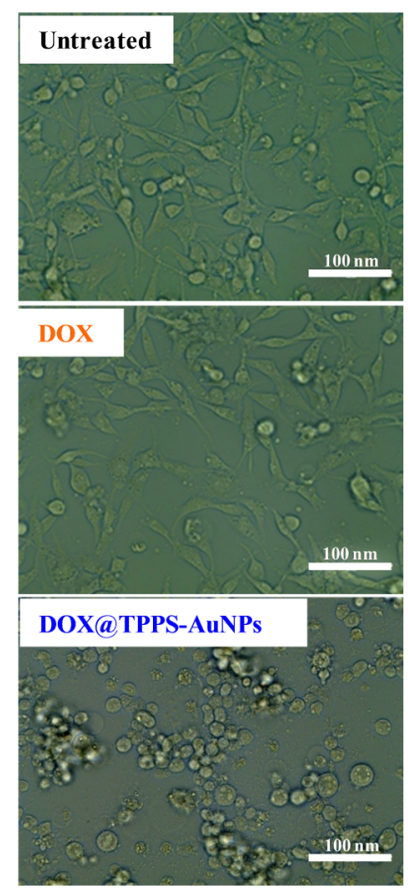

B

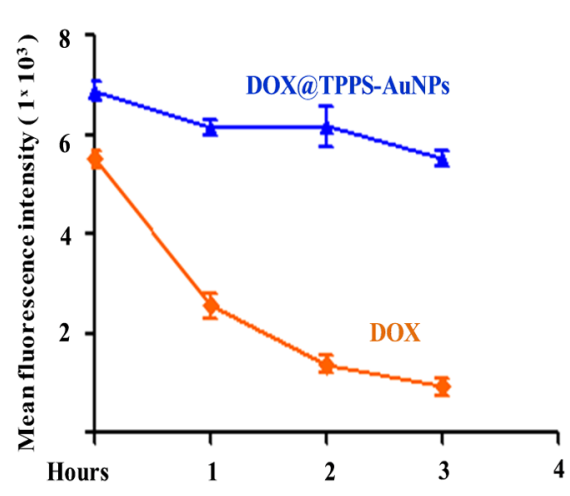

$\mathbf{E}$

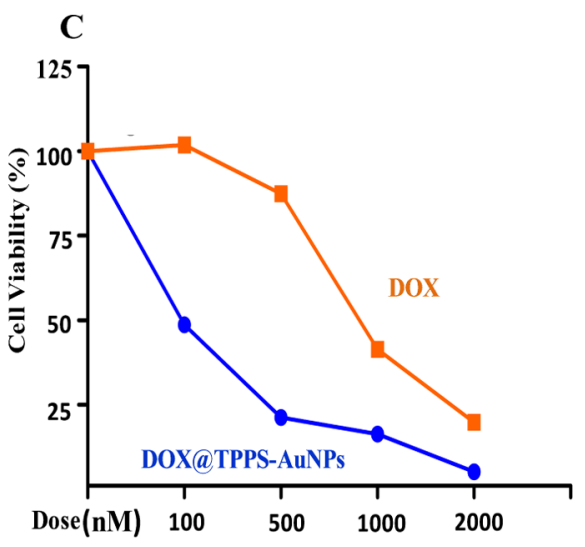

$\mathbf{F}$
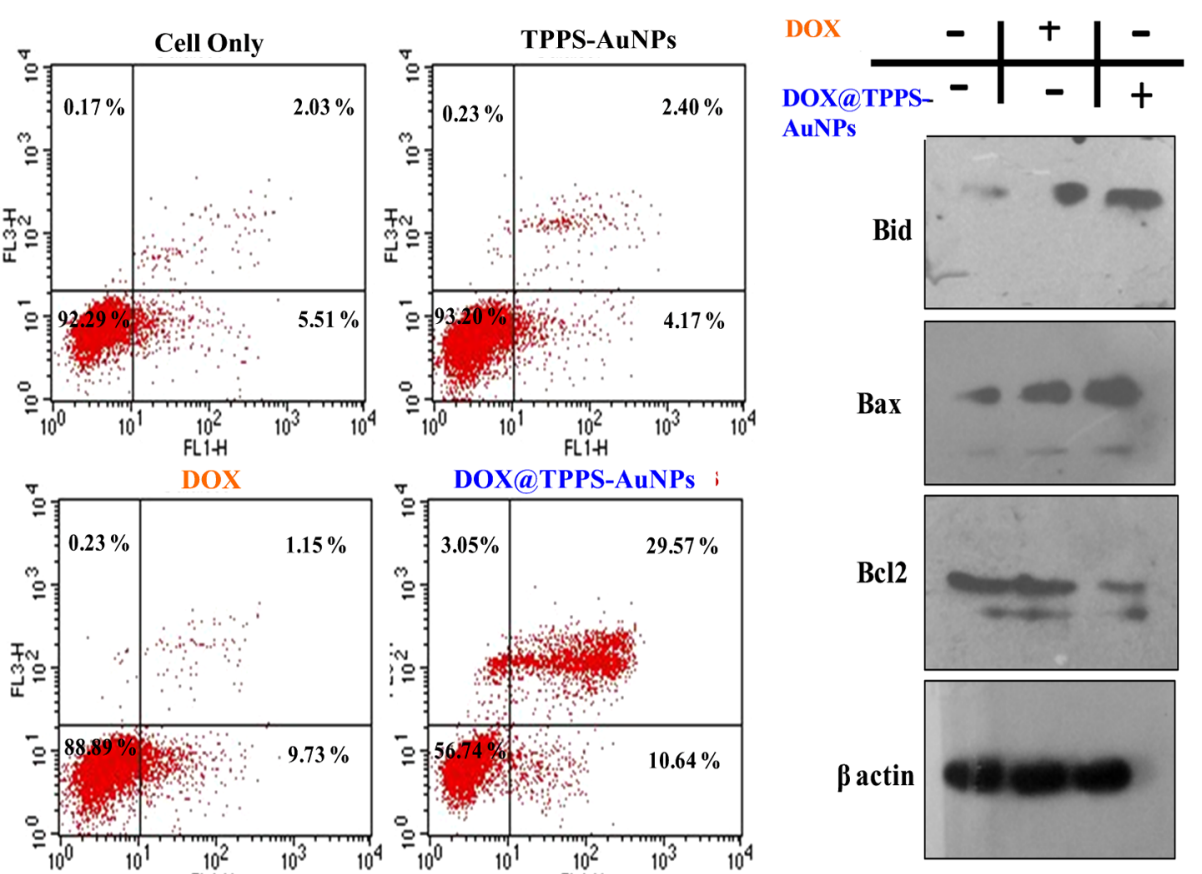

Figure 5. (A) Accumulation of total DOX in DOX- and DOX@TPPS-AuNP-treated MDR brain cancer cells (GBM, LN229). (B) DOX- and DOX@TPPS-AuNP-pretreated $(6 \mathrm{~h})$ LN229 were cultured in a complete medium without any drug. The concentration of DOX inside cells was measured at different time points by flow cytometry. (C, D) U87MG cells treated with free DOX or DOX@TPPS-AuNPs for 48 h. The 3-(4,5dimethylthiazol-2-yl)-2,5-diphenyltetrazolium bromide (MTT) assay showed DOX@TPPS-AuNPs having half-maximal inhibitory concentration $\left(\mathrm{IC}_{50}\right) \sim 9$-fold lower than that of free DOX (C). Inverted light microscopy showed morphological changes (D). (E) Higher annexin V/propidium iodide (PI)-positive U87MG in the upper right quadrant indicating more apoptosis when treated with DOX@TPPS-AuNPs compared to that with free DOX. (F) Western blots showing upregulation of proapoptotic (Bax/Bid) and downregulation of anti-apoptotic (Bcl2) proteins in DOX@ TPPS-AuNP-treated U87MG.

TPPS-AuNPs separately at different time intervals and the quantity of DOX inside the cells was determined by flow cytometry (Figure 5A). The fluorescence intensity was $\sim 5$-foldenhanced when the cells were incubated with DOX@TPPSAuNPs compared to that with free DOX even after $2 \mathrm{~h}$ incubation, suggesting higher amount of DOX internalization, which reached plateau after $6 \mathrm{~h}$. In contrast, cells treated with free DOX took a longer time to reach the plateau because of its poor uptake in LN229 cells. Thus, it may be stated that DOXloaded NPs elicit their effect more prominently by increasing the cellular uptake within a short span of time and could be beneficial to reduce the drug toxicity as well as efficient delivery.

We further determined the retention time of DOX in LN229 cells when the drug was delivered as doxorubicin-tethered
AuNPs. Accordingly, cells were incubated with either free DOX or DOX@TPPS-AuNPs for $4 \mathrm{~h}$. They were subsequently washed with PBS to remove uninternalized free drug or DOX@ TPPS-AuNPs. The cells were further incubated in fresh complete medium for different periods of time $(1-4 \mathrm{~h})$. We maintained the initial dose $(500 \mathrm{nM})$ of doxorubicin during treatments with DOX@TPPS-AuNPs. However, we intentionally increased the initial concentration of doxorubicin to $4 \mu \mathrm{M}$ when free DOX was used for treatment to increase the initial cellular concentration of this drug. As shown in Figure 5B, a fast decrease in the intracellular doxorubicin level was observed in LN229 cells preincubated with free doxorubicin because of rapid drug efflux. However, the amount and the efflux rate of doxorubicin were significantly lower when the cells were 
preincubated with DOX@TPPS-AuNPs, indicating that the efflux of drug was decreased upon its coupling with TPPSAuNPs. These results demonstrated that doxorubicin is protected against efflux when attached with TPPS-AuNPs and thus the nanoparticles increased the cellular retention of doxorubicin in LN229 cells. As porphyrins are essential cofactors of many human proteins including hemoglobin and myoglobin, we expect that TPPS-modified gold nanoparticles can escape their uptake by macrophages and may retain in the system for a longer time and thus could be useful in vivo.

The successful delivery of doxorubicin into the cancer cell is reflected by monitoring the cell viability. The range of concentrations selected was that which was frequently used for biomedical applications of AuNPs, where $200 \mu \mathrm{g} / \mathrm{mL}$ or $400 \mathrm{nM}(100 \mu \mathrm{g} / \mathrm{mL})$ was used for in vitro and $151 \mu \mathrm{g} / \mathrm{mL}$ for in vivo biodistribution studies. ${ }^{65,66}$ The cytotoxic effect depends on the size, shape, surface coating, and charge of gold nanoparticles. ${ }^{67-70}$ Regarding the size of the AuNPs, citratestabilized AuNPs of $5 \mathrm{~nm}$ have been shown to be cytotoxic at a concentration higher than $50 \mu \mathrm{M}$ with $\mathrm{Balb} / 3 \mathrm{~T} 3$ cells. $^{71}$ However, Vijayakumar et al. found that citrate-capped AuNPs having diameters $5,6,10,17$, and $45 \mathrm{~nm}$ did not decrease the cell viability of MCF-7 and PC-3 cells. ${ }^{69}$ Furthermore, TATmodified AuNPs having diameters 3.8 and $22.1 \mathrm{~nm}$ showed very low toxicity in $\mathrm{HepG}_{2}$ cells. $^{70}$ AuNPs with $15-150 \mathrm{~nm}$ diameters are also biocompatible, and only certain $150 \mathrm{~nm}$ PEG-functionalized particles reduced the viability at high concentrations. ${ }^{72}$ Huo et al. showed that nanoparticles smaller than $10 \mathrm{~nm}(2$ and $6 \mathrm{~nm})$ could preferentially enter the nucleus of the MCF-7 breast cancer cell. ${ }^{73}$ The size-dependent gold nanoparticle interaction at the nano-micro interface showed that smaller AuNPs had a lower uptake compared to that of larger NPs at a monolayer cell level. However, the order was reversed at a tissuelike multilayer level. The smaller NPs penetrated better compared with larger NPs in tissuelike materials. ${ }^{74}$ Cytotoxicity studies including $3,10,25$, and $50 \mathrm{~nm}$ of AuNPs into the HEp-2 cells indicated that after $1 \mathrm{~h}$ incubation 3 and $10 \mathrm{~nm}$ particles entered the nucleus, whereas 25 and $50 \mathrm{~nm}$ particles accumulated around the nucleus. ${ }^{75}$ Furthermore, the shape of the nanoparticles has a marked effect on AuNP toxicity. Rod-shaped AuNPs demonstrate more toxicity than their spherical counterparts. Gold nanorods are more toxic to human keratinocyte cells compared with spherical gold nanomaterials. ${ }^{4}$ Properly functionalized AuNPs not only can serve as a drug reservoir but also can increase the circulation time of the drug in the blood stream. ${ }^{76-78}$ Therefore, suitable modification of the AuNP surface can reduce cellular toxicity, which is associated with chemical surfactants used during the synthesis of the NPs. ${ }^{79,80}$ The $\zeta$ potential on the surface of nanoparticles can also influence AuNP toxicity. Cationic AuNPs are moderately toxic compared with anionic AuNPs; however, toxicity of both cationic and anionic AuNPs toward cells is also reported.

Considering all of these points, first, we addressed whether the nanoparticle itself has any toxic effect or not. Accordingly, we treated the normal lung fibroblast (WI38) and nonsmall-cell lung cancer (A549) with different doses of TPPS-AuNPs for 72 $\mathrm{h}$ in complete medium (Figure S6). Even upto $200 \mu \mathrm{M}$ concentrations, the empty nanoparticle showed no toxicity toward both the normal and cancer cells, as determined by the MTT assay. These results shows that TPPS-coated $10 \mathrm{~nm}$ diameter AuNPs do not induce any acute cytotoxic effects in the cells, which provides new opportunities for the safe application in drug delivery.

Previously, we showed an acid-responsive release of the drug from the nanoparticle surface (Figure $4 \mathrm{E}$ ). The core of the tumor is acidic, and many drugs fail to reach that place; therefore, delivery of DOX by DOX@TPPS-AuNPs may rapidly increase the concentration of the free drug in cancer cells and will enhance the cytotoxicity. Accordingly, we incubated various doses of free DOX and DOX@TPPSAuNPs with two representative cancer cells having various mutations, namely, A549 and glioblastoma multiforme (GBM) cell lines (U87MG), and determined the half-maximal inhibitory concentration $\left(\mathrm{IC}_{50}\right)$ of doxorubicin by the MTT assay. Both free DOX and DOX@TPPS-AuNPs were used with the same concentration of DOX. They exhibited a significant cytotoxic effect in a dose-dependent manner (Figures 5C and S7). The $\mathrm{IC}_{50}$ values were 80 and $94 \mathrm{nM}$ for DOX@TPPSAuNPs and 560 and $840 \mathrm{nM}$ for free DOX in A549 and U87MG cells, respectively, after 48 under similar conditions. We found that DOX@TPPS-AuNPs showed 7- and 9-fold better efficacies in A549 and U87MG cells compared with free DOX. Furthermore, drastic morphological changes in these cells treated with an equal concentration (100 nM) of DOX@ TPPS-AuNPs compared to those with free DOX for $48 \mathrm{~h}$ were visualized under light microscopy (Figure 5D). The DOX@ TPPS-AuNP-treated cells exhibited more cell shrinkage. These cells appeared as round or oval and smaller in size. The cytoplasm of these cells was dense, and the organelles were more tightly packed. All of these morphological changes are the sign of cell death. Only DOX at the similar dose and time point did not show such an effect, indicating that TPPS-AuNPs can even reduce the time span of treatment. Thus, the reduction of doses using TPPS-AuNPs would be beneficial. In addition, we similarly treated normal cells (WI38 and SVG) at $\mathrm{IC}_{50}$ doses at different time points. We found that these cells were not at all affected with DOX@TPPS-AuNPs even after 72 h incubation, whereas free DOX showed toxicity to normal cells at $\mathrm{IC}_{50}$ concentration (Figures S8 and S9).

We also investigated whether the nanoparticle-encapsulated DOX is showing the programed cell death (apoptosis) or necrosis. ${ }^{81}$ The detection of apoptosis was assessed by the binding of annexin V/PI with the externalized phosphotidylserine to the outer surface of plasma membrane. Here, we observed loss of membrane integrity of DOX@TPPS-AuNPtreated U87MG cells, as indicated by both annexin V and PI (29.57\%) positivity compared to that in free doxorubicin treatment $(1.1 \%)$, indicating late apoptosis as shown in Figure 5E. This data demonstrated that DOX@TPPS-AuNPs are capable of killing cancer cells via programmed cell death. For further validation, we checked two proapoptotic (Bax and Bid) and one representative anti-apoptotic $(\mathrm{Bcl} 2)$ molecules in their protein level (Figure 5F). We found enhanced levels of Bid and Bax and a decrease of Bcl2 in DOX@TPPS-AuNP-treated cells, confirming induction of apoptosis. These results proved that DOX@TPPS-AuNPs have a higher therapeutic effect than that of free doxorubicin. Consequently, TPPS-AuNPs could improve the therapeutic effect of DOX and served as a good drug carrier.

Metastasis is one of the major problems through which cancer cells travel to different organs of body and thereby generate secondary tumor. Invasion and migration of cancer cells are the two main properties for establishing metastasis. Angiogenesis is another process through which cancer cells 


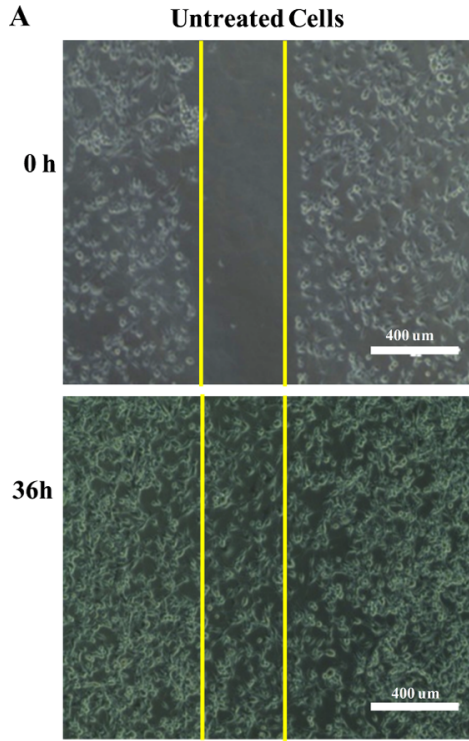

C

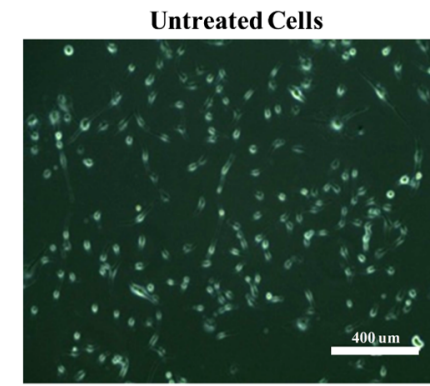

E

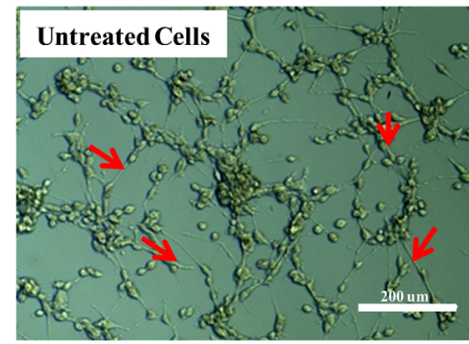

DOX
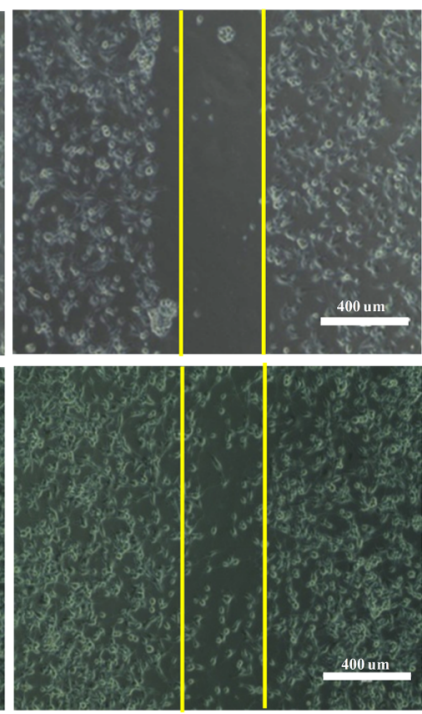

DOX
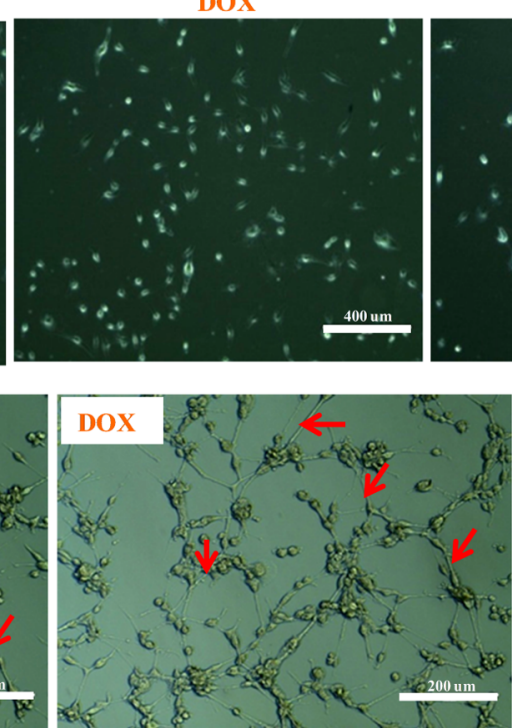

DOX $@$ TPPS-AuNPs

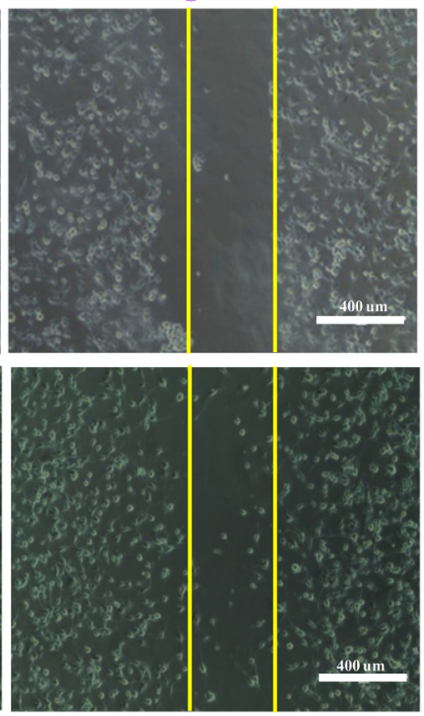

DOX@TPPS-AuNPs

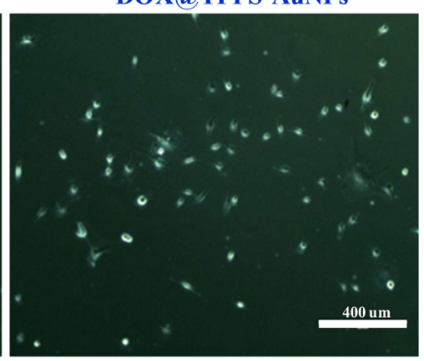

B

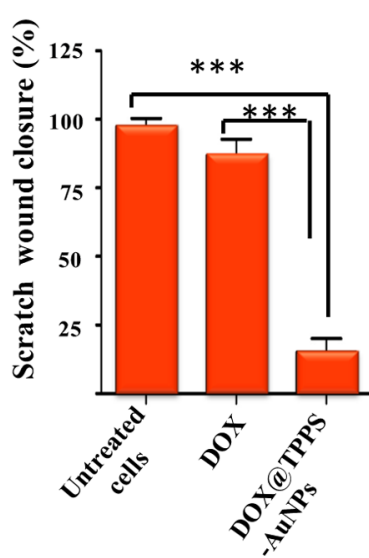

D

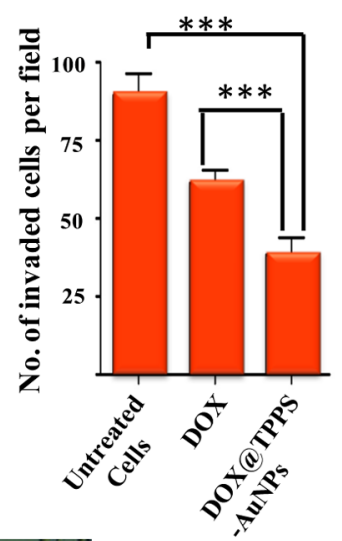

Figure 6. (A, B) Scratch wound assay performed by making similar scratches on plates of confluent U87MG cells and the cells treated with free DOX and DOX@TPPS-AuNPs separately for 36 h. DOX@TPPS-AuNP-treated U87MG showed lower scratch-wound closure, indicating lower migration. (C, D) DOX@TPPS-AuNPs/DOX-treated U87MG cells kept in an upper chamber of matrigel-coated insert systems to check the invasion ability. Cells that invade the membrane were counted. DOX@TPPS-AuNP-treated cells showed lower invasion ability to the membrane compared to that of free DOX. (E) DOX@TPPS-AuNP-treated U87MG cells showing a weaker threadlike structure compared to that of free DOX (red arrow), indicating inhibition of angiogenesis.

generate new blood vessels for their emerging necessity of nutrients. Therefore, it is necessary to reduce metastasis and angiogenesis to inhibit the growth of tumor. Accordingly, we checked the ability of DOX@TPPS-AuNPs to reduce migration, invasion, and angiogenesis properties of cancer cells. Scratch wounds were made through the $>80 \%$ confluent U87MG cells in a six-well plate. They were incubated with free DOX and DOX@TPPS-AuNPs separately for $36 \mathrm{~h}$. We found that cells treated with DOX@TPPS-AuNPs were unable to migrate to that scratch area, whereas untreated and free DOXtreated cells were able to migrate (Figure 6A,B). We further determined the invasion ability of cells treated with free DOX and DOX-loaded TPPS-AuNPs using matrigel-coated insert systems. Cells that invaded the membrane and adhered to the lower surface are considered for invading tissues. Three randomly selected fields on the lower side of the insert were photographed, and the migrated cells were counted (Figure 6C,D). The DOX-TPPS-AuNP-treated cells showed reduced invasion in comparison to that from free DOX. In addition, we compared both DOX-TPPS-AuNP- and DOX-treated cells for their capacity to form a connective tube, which is a signature of angiogenesis. U87MG cells form threadlike connective tubes between cellular colonies. However, at similar doses of free DOX and DOX-TPPS-AuNPs, treated cells showed weak connective tube formation ability (Figure 6E), which helps kill the cells easily. Therefore, free DOX when conjugated with TPPS-AuNPs exhibited reduction in migration, invasion, and angiogenesis properties compared to those of free DOX alone. Thus, the nanoparticle-conjugated doxorubicin cells can halt metastasis and angiogenesis of cancer cells at a much lower dose. 
$\mathbf{A}$
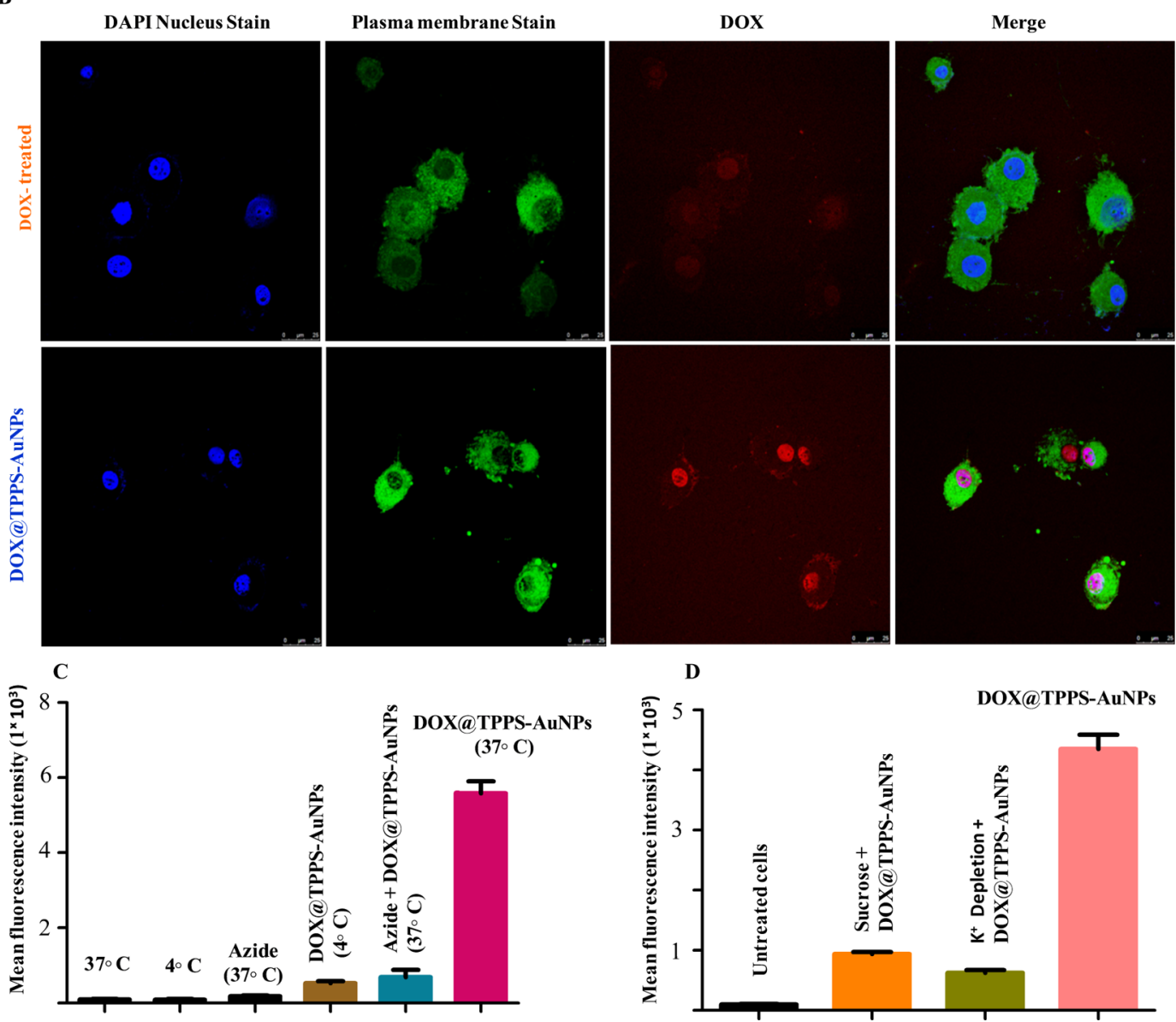

D

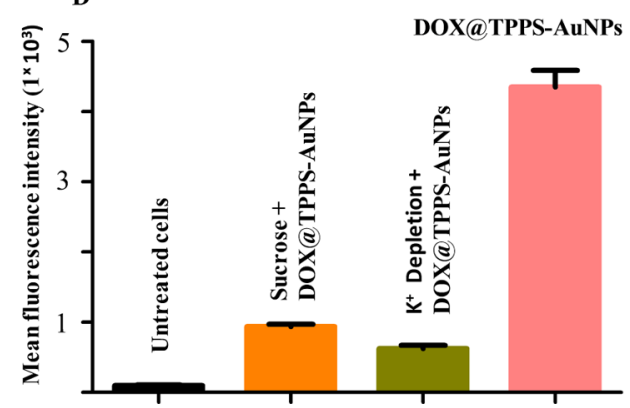

Figure 7. (A) Uptake of DOX in LN229 with/without preincubation against DOX@TPPS-AuNPs at pH 5.0 ( 1 h). (B) Confocal microscopy of U87MG counterstained with DAPI (blue) and CellMask Deep Red (green) showing higher accumulation of DOX (red) in the nucleus (indicated in merged orange) of DOX@TPPS-AuNP-treated cells (12 h). (C) Sodium azide-pretreated LN229 cells incubated with DOX@TPPS-AuNPs at 4 and $37^{\circ} \mathrm{C}$. (D) Cells pretreated with $0.45 \mathrm{M}$ sucrose and $\mathrm{K}^{+}$-depleted medium separately and cultured with DOX@TPPS-AuNPs in complete medium. In all of the experiments, the concentration of DOX was determined by flow cytometry.

We also investigated whether doxorubicin could be released from DOX@TPPS-AuNPs in response to the intracellular acidic microenvironment. We mixed DOX-tethered AuNPs with the culture medium at $\mathrm{pH} 5.0$ for $1 \mathrm{~h}$ and adjusted the $\mathrm{pH}$ back to $\mathrm{pH}$ 7.4. This medium was then added to MDR brain cancer cells (LN229), and the cells were cultured for another 2 h. For comparison, we treated these cells with DOX@TPPSAuNPs in regular complete medium. Pretreated (at acidic $\mathrm{pH}$ ) DOX@TPPS-AuNPs exhibited a significantly lower uptake of DOX compared to that for DOX@TPPS-AuNPs at physiological $\mathrm{pH}$, as measured by flow cytometry (Figure 7A). This is because the extracellular pretreatment at $\mathrm{pH} 5.0$ led to partial release of doxorubicin. This extracellular doxorubicin could not be effectively retained in LN229 cells without carrier. In addition, confocal microscopy provided visible evidence of acidresponsive intracellular release of doxorubicin from DOX@ TPPS-AuNPs (Figure 7B). Cells incubated with free DOX for $12 \mathrm{~h}$ showed only faint red fluorescence signals, whereas more fluorescence was observed in DOX@TPPS-AuNP-treated cells, indicating enhanced entry of doxorubicin into the nucleus. Doxorubicin, being a DNA intercalator, should accumulate in the nucleus. The interaction of doxorubicin with DNA by 
intercalation is one of the major modes of action. Therefore, the accumulation of doxorubicin in the nucleus is a necessary prerequisite. Close scrutiny of the images revealed that the fluorescence signal from cells treated with DOX@TPPS-AuNPs was significantly stronger than that from the control groups which were more dispersed in the perinuclear region. In cancer cells, the nucleus is more acidic, whereas in normal cells, the nucleus is more alkaline than the cytoplasm. That is why in cancer cells, there is release of more doxorubicin from the conjugates, playing a crucial role in the growth inhibition of cancer cells. The lower fluorescence signal within the nucleus was observed when the cells were incubated with free DOX, indicating that the release of doxorubicin is lower.

In addition, we addressed the internalization mechanism of DOX@TPPS-AuNPs into LN229 cells. Endocytosis is known to be one of the important entry mechanisms for various extracellular materials. This is an energy-dependent mechanism and can be hampered at low temperatures (e.g., $4{ }^{\circ} \mathrm{C}$ instead of $37{ }^{\circ} \mathrm{C}$ ) or under adenosine $5^{\prime}$-triphosphate (ATP)-depleted conditions. Treatment with $\mathrm{NaN}_{3}$ is known to perturb ATP production in cells, thus affecting the endocytotic pathway. As shown in Figure 7C, incubation of DOX@TPPS-AuNPs at 4 ${ }^{\circ} \mathrm{C}$ for $2 \mathrm{~h}$ and with $\mathrm{NaN}_{3}$ (ATP-depleted)-pretreated cells showed significantly reduced internalization compared to that under regular culture conditions. This result suggested that DOX@TPPS-AuNPs entered into the cells via energy-dependent endocytosis. Receptor-mediated endocytosis occurs through clathrin-dependent invagination of the plasma membrane. ${ }^{79}$ To prove further, we either pretreated the cells with sucrose (hypertonic treatment) or a $\mathrm{K}^{+}$-depleted medium prior to exposure to the DOX@TPPS-AuNPs. These conditions are known to disrupt the formation of clathrincoated vesicles on the cell membrane. These pretreatments drastically reduced the level of cellular uptake of DOX@TPPSAuNPs, as deduced by flow cytometry (Figures 7D and S10). These observations suggested the clathrin pathway for endocytotic cellular uptake of DOX@TPPS-AuNPs. As the endocytic compartments are acidic, an efficient release of DOX occurs when DOX@TPPS-AuNPs are taken up by the cancer cells via endocytosis. Therefore, a sufficiently high concentration of DOX can be released from the NP surface when it is taken up by the tumor cell through an endocytosis mechanism, thereby greatly improving the efficacy of targeted cancer therapy and enhancing the cell cytotoxicity.

\section{CONCLUSIONS}

Except a few reports, the ability of porphyrin-conjugated AuNPs to deliver the drug to the tumor cells has not been investigated thoroughly. Majority of the studies focused on the optical properties of porphyrin nanoclusters and their photosensitizing behavior for photodynamic therapy. We have developed a porphyrin-based gold nanocarrier, which can efficiently bind to doxorubicin and effectively release the drug molecules inside cancer cells. The embedment of TPPS on the gold nanosurface through coordination interaction via porphyrin pyrrolic nitrogens resulted in an increase in the stability and solubility of the nanosystem. We further validated its in vitro internalization using different cancer cells, which showed enhanced efficacy of known cancer drugs by enhanced drug delivery. DOX@TPPS-AuNPs exhibited strong tumor growth inhibition and more effective apoptosis of cancer cells compared to those of free DOX. DOX-loaded nanoparticles reduced angiogenesis and metastasis of cancer cells to a higher degree than free DOX. TPPS-AuNPs reduced the effective drug concentration to a certain level, at which normal cells were less affected. Thus, TPPS-AuNPs served dual roles: first, they reduced the concentration/dose level and second, they help in the accumulation of the loaded drug molecule preferentially in the nucleus of the diseased cell and therefore became capable of overcoming the drug resistance. Therefore, TPPS-AuNPs with a higher drug encapsulation efficacy and release of drug at the nucleus of tumor cells act as a "magic bullet" and may have an immense implication in cancer therapy.

\section{EXPERIMENTAL SECTION}

Materials and Methods. All chemicals used were of analytical grade or of highest purity available and used as received. Hydrogen tetrachloroaurate(III) hydrate $\left(\mathrm{HAuCl}_{4}\right.$. $3 \mathrm{H}_{2} \mathrm{O}$ ), tetrasodium salt of meso-tetrakis(4-sulfonatophenyl)porphyrin $\left(\mathrm{C}_{44} \mathrm{H}_{26} \mathrm{~N}_{4} \mathrm{Na}_{4} \mathrm{O}_{12} \mathrm{~S}_{4} \cdot x \mathrm{H}_{2} \mathrm{O}\right)$, HEPES buffer, antibiotic-antimycotic mixture, annexin $\mathrm{V}$, and propidium iodide (PI) matrigel were from Sigma-Aldrich. Sodium hydroxide $(\mathrm{NaOH})$ and sodium borohydride $\left(\mathrm{NaBH}_{4}\right)$ were from Merck Millipore. The glassware was carefully cleaned with aqua regia $\left(3: 1 \mathrm{HCl} / \mathrm{HNO}_{3}\right)$ and then rinsed several times with HPLC water prior to use under sonication. HPLC water was used to prepare all of the solutions. Iscove's modified Dulbecco's medium (IMDM), fetal bovine serum (FBS), Super Signal West Pico imaging system, and CellMask Deep Red Plasma membrane Stain were from Thermo Fisher Scientific. All of the antibodies were from Cell Signaling Technology. Protease and phosphatase inhibitor cocktails were from Calbiochem. Cell cultures insert and flasks were from BD Bioscience.

Synthesis of TPPS-AuNPs. Preparation of simple gold nanoparticles of different sizes and shapes is reported earlier in different contexts. ${ }^{80,82-85}$ A few studies showed formation of gold nanoparticles and nanoclusters using functionalized porphyrin molecules. ${ }^{26,30,39,86,87}$ We utilized a simple protocol to prepare gold nanoparticles armored with an electron-rich porphyrin macrocyclic ring. Bare gold nanoparticles (AuNPs) were prepared using the standard sodium borohydride $\left(\mathrm{NaBH}_{4}\right)$ reduction method. Gold chloride solution $(10 \mu \mathrm{L}$; $1.47 \mathrm{M}$ ) was added to $30 \mathrm{~mL}$ of water in a round bottom flask, and the $\mathrm{pH}$ of the solution was adjusted to $\sim 9.0$ by dropwise addition of $0.5 \mathrm{M} \mathrm{NaOH}$ solution. The final concentration of $\mathrm{Au}^{3+}$ was $0.5 \mathrm{mM}$. The solution was stirred for $15 \mathrm{~min}$. Subsequently, the reaction mixture was placed on an ice bath and $50 \mathrm{mM} \mathrm{NaBH}_{4}$ solution in water was slowly added to the reaction mixture. The molar ratio of $\mathrm{Au}^{3+}$ to $\mathrm{BH}_{4}^{-}$was $1: 2$. The reaction mixture turned pinkish red, indicating the formation of gold nanoparticles (AuNPs). To avoid coagulation of particles, the reaction mixture was placed on an ice bath. The reaction mixture was continuously stirred for additional $4 \mathrm{~h}$ to complete the reaction. The resulting mixture was centrifuged for $10 \mathrm{~min}$ at $15000 \mathrm{rpm}$ and gold nanoparticles were collected in a pellet form, as precipitated.

To prepare porphyrin-embedded gold nanoparticles (TPPSAuNPs), $600 \mu \mathrm{M}$ aqueous solution of the tetrasodium salt of meso-tetrakis(4-sulfonatophenyl)porphyrin (TPPS) (Scheme $1 \mathrm{~A})$ was prepared in a falcon tube and covered with aluminum foil. This solution $(5 \mathrm{~mL})$ was added to AuNP suspension (5 $\mathrm{mg}$ in $5 \mathrm{~mL} \mathrm{H}_{2} \mathrm{O}$ ) in a round bottom flask in one addition, and the $\mathrm{pH}$ of the solution was adjusted to $\sim 9.0$ by adding $0.01 \mathrm{M}$ $\mathrm{NaOH}$ solution. The solution was stirred continuously (1100 $\mathrm{rpm}$ ) for $24 \mathrm{~h}$ under dark conditions (covered with aluminum foil). The weight ratio of AuNPs to TPPS was 1.7:1. The 
TPPS-conjugated gold nanoparticles (TPPS-AuNPs) were collected by centrifugation ( $\mathrm{rpm}$ of $15000,15 \mathrm{~min}$ ). The sample was washed once/twice to remove most of the unbound TPPS molecules. Multiple washing was avoided to prevent coagulation. The embedment of the porphyrin into the nanosurface was reflected in the broadening of the SPR band (discussed in the Results and Discussion section). The collected nanocomposite remained pinkish red in aqueous suspension. The purified nanoparticles were re-dispersed in water and used for further characterization, and their ability to deliver doxorubicin into the cancer cells was tested.

Transmission Electron Microscopy (TEM). The size distribution and morphology of TPPS-AuNPs were characterized by high-resolution transmission electron micrograph (HRTEM). For HRTEM imaging, the drop-casting method was used, in which an aqueous suspension of the prepared gold nanoparticles (TPPS-AuNPs) and the nanochemotherapeutic system (DOX@TPPS-AuNPs) were placed on a carbon-coated 300-mesh copper grid (Allied Scientific Product), and it was dried in a dust-free atmosphere. The electron microscopy images of the sample were taken using a JEOL JEM $2100 \mathrm{HR}$ with electron energy loss spectroscopy instrument followed by an acceleration voltage of $200 \mathrm{kV}$.

DLS and $\zeta$ Potential Study. The mean hydrodynamic diameter and charge of the nanoparticles were determined using a Nano-ZS (Malvern Instruments, Worcestershire, U.K.) at $25{ }^{\circ} \mathrm{C}(5 \mathrm{~mW}, \mathrm{He}-\mathrm{Ne}$ laser, $\lambda=632 \mathrm{~nm})$. The operating procedure was programmed using DTS software supplied with the instrument to record the average of 20 runs. Every run was collected for $30 \mathrm{~s}$, and an equilibration time of $5 \mathrm{~min}$ was used.

Isothermal Calorimetric Titration. The binding of AuNPs to TPPS was studied by isothermal titration calorimetry (ITC) using a MicroCal VP-ITC unit (MicroCal, Inc., Northampton, MA, Now Malvern Instruments, Malvern, U.K.). To avoid air bubble formation during the course of titration, TPPS and nanoparticles solution were degassed on MicroCal's Thermovac unit before loading. The calorimeter syringe was filled with the TPPS solution $(1.8 \mathrm{mM})$, and the calorimeter cell, with $1.42 \mathrm{~mL}$ of the AuNP suspension (100 $\mu \mathrm{g} / \mathrm{mL}$ ). Successive injections (10 $\mu \mathrm{L}$ aliquots) of the TPPS solution into the AuNP suspension were performed by the rotating syringe $(416 \mathrm{rpm})$. Control experiments were performed to determine the heat of dilution of the TPPS solution, and these values were subtracted from the integrated data before curve fitting. The area under each heat burst curve was determined by integration using Origin software to provide the heat associated with the injections. The resulting corrected injection heats were plotted as a function of the molar ratio, fit with a "single-site binding model", and analyzed to give the binding affinity $\left(K_{\mathrm{a}}\right)$ and the standard molar enthalpy change $\left(\Delta H^{\circ}\right)$ of the binding. The standard molar Gibbs free energy $\left(\Delta G^{\circ}\right)$ and the entropy contribution to the binding $\left(T \Delta S^{\circ}\right)$ were subsequently calculated by the following equation

$$
\Delta G^{\circ}=\Delta H^{\circ}-T \Delta S^{\circ}
$$

where $T$ is the temperature in kelvin. The calorimeter was periodically calibrated electrically; the mean energy per injection was $\leq 1.30 \mu \mathrm{cal}$, and the standard deviation was $\leq 0.015 \mu \mathrm{cal}$. The experimental data were analyzed by dedicated Origin 7.0 software.

FT-IR Investigation. A Bruker TENSOR27 spectrometer was used to record the FT-IR spectra of the samples using the $\mathrm{KBr}$ pellet technique. The solid sample (TPPS/TPPS-AuNPs) was mixed with $\mathrm{KBr}$ under pressure, and a solid and thin pellet was obtained. The spectra were recorded in the frequency range of $400-4000 \mathrm{~cm}^{-1}$. For each sample, background spectra were obtained with only $\mathrm{KBr}$ pellet. The experimental data were processed using Bruker software.

Synthesis of DOX-Loaded TPPS-AuNPs. A doxorubicinloaded nanochemotherapeutic system (DOX@TPPS-AuNPs) was prepared by mixing TPPS-AuNPs with doxorubicin (Scheme 1B) in aqueous medium. Freshly prepared TPPSAuNPs $(\sim 2 \mathrm{mg})$ were dispersed in $15 \mathrm{~mL}$ of water taken in a round bottom flask. The DOX solution $(150 \mu \mathrm{L} ; 3 \mathrm{mM})$ at $\mathrm{pH}$ 7.4 was added to the above solution so that the final DOX concentration was $\sim 30 \mu \mathrm{M}$. The weight ratio of DOX to TPPSAuNPs was 1:7. The color of the solution changed from pinkish red to violet, confirming the association of DOX with the TPPS-AuNPs, forming the DOX@TPPS-AuNPs nanocomposite. The color change also indicated some increase in the size of the nanocomposite. The mixed solution was allowed to stir for $30 \mathrm{~h}$ at room temperature and centrifuged once at 10000 rpm for $10 \mathrm{~min}$ to remove the unbound drug. The DOX@ TPPS-AuNPs were collected in a pellet form. To calculate the DOX encapsulation efficiency (EE), the unloaded DOX remaining in the supernatant was quantified using a calibration curve for DOX as obtained by measuring the absorption of the free drug molecules of known concentration at $480 \mathrm{~nm}$.

The encapsulation efficiency (EE) of the process was measured as a function of time using the following equation. $^{88,89}$

$$
\mathrm{EE}=\left(\frac{C_{\text {total DOX }}-C_{\text {free DOX }}}{C_{\text {total DOX }}}\right) \times 100 \%
$$

where $C_{\text {total Dox }}$ is the total concentration of DOX $(\sim 30 \mu \mathrm{M})$ measured from a standard calibration curve for DOX at $480 \mathrm{~nm}$ and $C_{\text {free Dox }}$ is the concentration of unloaded DOX measured from the same calibration curve. The DOX@TPPS-AuNPs were again redispersed in $1 \mathrm{~mL}$ of HPLC water for further investigation.

DOX Release Study. To quantify the drug release, small aliquots (30 $\mu \mathrm{L})$ of DOX@TPPS-AuNPs from the stock suspension $(1 \mathrm{~mL})$ were rapidly added to equal volumes (1 $\mathrm{mL}$ ) of different buffer solutions with varying the $\mathrm{pHs}$ and thermo stating at $37^{\circ} \mathrm{C}$. For each $\mathrm{pH}$ buffer solution, we made six sets, and total 18 sets were prepared for three different $\mathrm{pH}$ buffers, each containing $1 \mathrm{~mL}$ of buffer solution and $30 \mu \mathrm{L}$ of stock DOX@TPPS-AuNPs. The solutions were gently shaken at $350 \mathrm{rpm}$. The different $\mathrm{pH}$ buffers $(10 \mathrm{mM})$ chosen for the investigation were $\mathrm{pH}$ 5.0, 6.0, and 7.4. Sodium citrate was used to make buffer at $\mathrm{pH} 5.0$, and sodium phosphate was used to make buffers at $\mathrm{pH} 6.0$ and 7.4.

At defined time intervals, each buffer solution was centrifuged with an rpm of 10000 for $10 \mathrm{~min}$, and the absorbance of the supernatant part was measured at $480 \mathrm{~nm}$ to determine the amount of DOX released. The percent of DOX released was calculated from absorbance of the solution and fitted them to the following equation

$$
\% \text { drug released }=\left(\frac{A_{\mathrm{t}}}{A_{0}}\right) \times 100 \%
$$

where $A_{\mathrm{t}}$ is the absorbance of released DOX at $480 \mathrm{~nm}$, measured at specific time intervals (between 0 and $40 \mathrm{~h}$ ), and 
$A_{0}$ is the absorbance of total DOX loaded onto TPPS-AuNPs at the same wavelength.

Absorption Spectroscopy. The optical absorption spectra of the synthesized TPPS-AuNPs and other solutions were recorded using a JASCO V-630 Spectrophotometer (JASCO International Co. Ltd., Japan) within the wavelength range of $300-700 \mathrm{~nm}$, and a high-quality quartz cuvette was used as a sample holder.

Fluorescence Spectroscopy. The steady-state fluorescence measurement of doxorubicin was performed by a Cary Eclipse fluorescence Spectrophotometer from Agilent Technologies. The machine was equipped with a Xenon lamp. DOX fluorescence measurement for the encapsulation/release study was carried out at a fixed excitation wavelength of $480 \mathrm{~nm}$, and the emission maximum was at $592 \mathrm{~nm}$. Both the excitation and emission slit widths were kept at $5 \mathrm{~nm}$, and a quartz cuvette of path length $1 \mathrm{~cm}$ was used for the fluorescence measurement. All of the experiments were carried out at room temperature $\left(25{ }^{\circ} \mathrm{C}\right)$. Fluorescence quenching of DOX in the presence TPPS-AuNPs indicated interaction and loading of the drug molecules to the nanoparticle. Fluorescence spectra of $30 \mu \mathrm{M}$ DOX (total) were recorded, and it was allowed to load on the TPPS-AuNP surface. After centrifugation, the fluorescence spectrum of unloaded DOX as present in the supernatant part was recorded. The fluorescence of DOX was found to be almost completely quenched in the presence of the nanocomposite. For DOX release measurements, DOX@TPPSAuNPs are dispersed in citrate buffer, $\mathrm{pH} \sim 5.0$ for $40 \mathrm{~h}$, and centrifuged $(10000 \mathrm{rpm}, 10 \mathrm{~min})$ and the fluorescence spectrum of the supernatant part was recorded upon excitation at $480 \mathrm{~nm}$ and the emission intensity was measured at $592 \mathrm{~nm}$.

Cell Lines and Culture Conditions. WI 38 (normal lung fibroblast), SVG (normal astrocytes), A549 (nonsmall-cell lung carcinoma), U87MG and LN229 (glioblastoma multiforme) cell lines were from ATCC, cultured in IMDM/minimum essential medium supplemented with 10\% FBS and 1\% antibiotic-antimycotic (complete medium), and maintained at $37{ }^{\circ} \mathrm{C}$ with $5 \% \mathrm{CO}_{2}$ in a carbon dioxide incubator.

Cell Viability Assay. WI 38 and A549 cells were treated with different doses of TPPS-AuNPs for $48 \mathrm{~h}$. We also tested the effect on U87MG, A549, SVG, and WI 38 cell lines when exposed to different doses of DOX and DOX@TPPS-AuNPs separately for $48 \mathrm{~h}$. Cell viability was determined by the MTT assay. ${ }^{90,91}$ The culture media were discarded, and MTT (1 mg/ $\mathrm{mL}, 100 \mu \mathrm{L} /$ well) was added to the wells, followed by incubation at $37{ }^{\circ} \mathrm{C}$ for $4 \mathrm{~h}$. The supernatant was removed. Dimethyl sulfoxide $(150 \mu \mathrm{L} /$ well $)$ was added to dissolve the formazan crystals produced by the viable cells, the plates were shaken for an additional $5 \mathrm{~min}$, and the absorbance of the purple color was recorded on a microplate reader (Thermo Scientific) at a wavelength of $550 \mathrm{~nm}$. The intensity of color indicates the number of viable cells.

Drug Uptake. LN229 cells $\left(1 \times 10^{6} / 2 \mathrm{~mL} /\right.$ well $)$ in complete medium were seeded in six-well plates and incubated overnight. The medium was then replaced with fresh medium with the absence and presence of DOX and DOX@TPPSAuNPs separately followed by incubation for $4 \mathrm{~h}$. The medium was removed. Cells were then washed two times with phosphate-buffered saline (PBS) with $\mathrm{pH} \sim 7.2$. The amount of DOX inside the cells was immediately analyzed by a FACS Calibur flow cytometer (Becton Dickinson, San Jose, CA). Data were collected and analyzed using CellQuest software (Becton Dickinson) as we did earlier. ${ }^{92,93}$
Cellular uptake of DOX and DOX@TPPS-AuNPs was determined by growing the cells $\left(5 \times 10^{5}\right)$ on coverslips in a six-well tissue culture plate for $24 \mathrm{~h}$. They were cultured in the presence of doxorubicin and doxorubicin-loaded TPPS-AuNPs at a concentration of $100 \mathrm{nM}$ separately for $12 \mathrm{~h}$. They were washed with PBS and fixed with 5\% paraformaldehyde in PBS. Canadian Balsam was dropped on the slides to seal the cell samples. Cells were then washed with PBS, and the coverslips stained with the CellMask Deep Red Plasma Membrane Stain were imaged using confocal laser scanning microscopy (Olympus FV1000).

Apoptosis Assay. Externalizations of phosphatidylserine were verified as described earlier. ${ }^{94,95}$ Briefly, U87MG cells (1 $\times 10^{6}$ ) were treated with either DOX or DOX@TPPS-AuNPs for $48 \mathrm{~h}$. Washed cells were resuspended in the annexin $\mathrm{V}$ binding buffer and kept for $45 \mathrm{~min}$ in the dark at $25{ }^{\circ} \mathrm{C}$ followed by incubation with fluorescein isothiocyanateannexin $\mathrm{V}$ and PI $(5 \mu \mathrm{g} / \mathrm{mL})$ for $20 \mathrm{~min}$ at $4{ }^{\circ} \mathrm{C}$ in the dark according to the manufacturer's instruction. Cells were acquired and analyzed by flow cytometry, as described above.

Immunoblotting. U87MG cells $\left(1 \times 10^{6}\right)$ were cultured to $>80 \%$ confluency in six-well plate. Untreated and treated cells $\left(1 \times 10^{6}\right)$ with DOX and DOX@TPPs-AuNPs (for $24 \mathrm{~h}$ ) were detached using a trypsin-ethylenediaminetetraacetic acid (EDTA) solution and centrifuged at $1500 \mathrm{rpm}$ for $5 \mathrm{~min}$. They were washed and lysed in ice-cold PBS with sonication (Qsonica-LLC, XL-2000 series). Cell lysates were centrifuged by cold centrifugation at $10000 \mathrm{rpm}$. The supernatants were used for western blotting. ${ }^{96-98}$

The proteins were quantified with the Bio-Rad protein assay kit and loaded equally onto sodium dodecyl sulfatepolyacrylamide gels (10\%). They were electrophoretically transferred to poly(vinylidene difluoride) membranes, as described earlier. ${ }^{99}$ After blocking with bovine serum albumin, the membranes were incubated with respective primary antibodies overnight under cold conditions. This was followed by incubation with appropriate secondary antibodies labeled with horseradish peroxidase. The signal was visualized using chemiluminescence detection. Developed bands were detected by a X-ray plate.

Migration Assay. The migration assay was done as described earlier. ${ }^{100}$ In brief, U87MG cells $\left(1 \times 10^{6}\right)$ were cultured to $>80 \%$ confluency in a six-well plate. Three separate scratch wounds were made through the confluent cells and washed thrice to remove cell debris. They were incubated with DOX and DOX@TPPS-AuNPs for $36 \mathrm{~h}$. The cell-free scratched area was calculated and represented as percent closure of area compared to that of untreated cells. Images were taken using inverted light microscopy.

Invasion Assay. The invasion assay was carried out as described earlier. ${ }^{100}$ In brief, U87MG cells $\left(1 \times 10^{6}\right)$ were cultured to $>80 \%$ confluency in a 12 -well plate. Cells were detached using the trypsin-EDTA solution and centrifuged at $1500 \mathrm{~g}$ for $10 \mathrm{~min}$. Washed cells $\left(1 \times 10^{6}\right)$ were treated with DOX and DOX@TPPs-AuNPs for overnight. Treated or untreated U87MG or LN229 cells $\left(5 \times 10^{4}\right)$ were suspended in a medium without FBS $(100 \mu \mathrm{L})$ and added to the upper chamber of an insert ( $6.5 \mathrm{~mm}$ diameter, $8 \mu \mathrm{m}$ pore size $)$. The insert was placed in a 24 -well plate containing the medium (700 $\mu \mathrm{L}$ ) with or without 10\% FBS. DOX and DOX@TPPS-AuNPs were added to both the upper and the lower chambers. The invasion was monitored after $36 \mathrm{~h}$, and cells were fixed with $3.7 \%$ formaldehyde. They were stained with crystal violet 
solution. Cells on the upper side of the insert were removed with a cotton swab. Three randomly selected fields (10 objectives) on the lower side of the insert were photographed, and the migrated cells were counted. The invasion was expressed as an average number of invaded cells in a field.

Angiogenesis Assay. The angiogenesis assay was carried out as described earlier. ${ }^{101}$ In brief, a thin layer of matrigel in $\operatorname{IMDM}(1: 3)$ was formed in a 12 -well plate. U87MG cells $(4 \times$ $10^{4}$ ) were layered over matrigel in a serum-free medium in a six-well plate. These cells have potentiality to form connective tissues in between cells. Cells were cultured for $48 \mathrm{~h}$ to form connective tissues. These cells were treated with DOX and DOX@TPPS-AuNPs separately and kept for another $48 \mathrm{~h}$. Images of connective tubes were recorded by inverted light microscopy.

Endocytosis of DOX@TPPS-AuNPs. Experiments for cellular endocytosis study were carried out as described earlier. ${ }^{102-104}$ Cells were incubated with DOX@TPPS-AuNPs (100 nM) under different conditions to inhibit the endocytosis mechanism as described below using representative drugresistant GBM cells (LN229) followed by monitoring the entry of DOX by FACS.

Low-Temperature Incubation. LN229 cells were incubated with DOX@TPPS-AuNPs (100 nM) in complete medium at $4{ }^{\circ} \mathrm{C}$, instead of at the physiological $37{ }^{\circ} \mathrm{C}$ temperature, to keep them in a metabolically less active condition, and the uptake was determined.

ATP Depletion. Cells were preincubated with $10 \mathrm{mM} \mathrm{NaN}_{3}$ and $50 \mathrm{mM}$ 2-deoxy-D-glucose in PBS buffer for $30 \mathrm{~min}$ at 37 ${ }^{\circ} \mathrm{C}$ followed by incubation in a solution of DOX@TPPSAuNPs (100 nM).

Hypertonic Incubation. Cells were preincubated with 0.45 $\mathrm{M}$ sucrose in PBS buffer for $30 \mathrm{~min}$ at $37^{\circ} \mathrm{C}$ before exposure to the DOX@TPPS-AuNPs (100 nM).

Potassium Depletion. The $\mathrm{K}^{+}$depletion was achieved as described earlier. ${ }^{104}$ Briefly, cells were washed once with a potassium-free buffer containing $140 \mathrm{mM} \mathrm{NaCl}, 20 \mathrm{mM}$ HEPES ( $\mathrm{pH} 7.4$ ), $1 \mathrm{mM} \mathrm{CaCl}, 1 \mathrm{mM} \mathrm{MgCl}$, and $1 \mathrm{mg} / \mathrm{mL}$ Dglucose. Subsequently, the cells were alternatively washed three times with the potassium-free buffer diluted with water (1:1; hypotonic buffer) and the potassium-free buffer. Then, the cells were incubated with DOX@TPPS-AuNPs (100 nM) in a potassium-free buffer or complete medium for $90 \mathrm{~min}$ at $37^{\circ} \mathrm{C}$. Control cells were treated similarly.

Statistical Analysis. All of the data were from at least three independent experiments, and statistical analysis was performed using Graph Pad Prism 5. The differences between the groups were analyzed by the two-tail student $t$-test or Mann-Whitney $U$-test. Standard error bars represent the standard deviation (SD) of the mean $( \pm \mathrm{SD})$, and $* p<0.05$ denoted the significant differences between the means of the untreated and treated cells or two test groups.

\section{ASSOCIATED CONTENT}

\section{S Supporting Information}

The Supporting Information is available free of charge on the ACS Publications website at DOI: 10.1021/acsomega.8b00419. $\zeta$ potentials of AuNPs and TPPS-AuNPs (Figure S1), hydrodynamic diameter of TPPS-AuNPs (Figure S2), FT-IR spectra of TPPS and TPPS-AuNPs (Figure S3), kinetics of encapsulation efficiency of DOX on AuNPs (Figure S4), hydrodynamic diameter and $\zeta$ potential of
DOX@TPPS-AuNPs (Figure S5), cell viability of A 549 and WI-38 cells after treatment with TPPS-AuNPs (Figure S6), cell viability of A549 cells after treatment with DOX and DOX@TPPS-AuNPs (Figure S7), inverted light microscopy images of WI-38 and SVG cells treated with DOX@TPPS-AuNPs (Figure S8), cell viability of WI-38 and SVG cells treated with DOX@ TPPS-AuNPs (Figure S9), and flow cytometry analysis of the cells using DOX@TPPS-AuNPs in sucrose and $\mathrm{K}^{+}$depleted medium (Figure S10) (PDF)

\section{AUTHOR INFORMATION}

\section{Corresponding Authors}

*E-mail: chitra_mandal@yahoo.com. Tel: +91-33-2429-8861. Fax: +91-33-2473-5197 (C.M.).

*E-mail: ncmaiti@iicb.res.in. Phone: +91-33-2499-5940. Fax: +91-33-2473-5197 (N.C.M.).

ORCID $\odot$

Chitra Mandal: 0000-0001-8275-3978

Nakul C. Maiti: 0000-0002-8498-6502

Author Contributions

${ }^{\S}$ K.B. and S.M. contributed equally.

Notes

The authors declare no competing financial interest.

\section{ACKNOWLEDGMENTS}

S.M. and K.B., senior research fellows, are thankful to the University Grant Commission and Department of Science and Technology, respectively, for providing fellowship. C.M. is grateful to the financial support by Sir J.C. Bose National Fellowship, DST, Government of India and DBT-Distinguished Biotechnology Research Professorship award. The work is supported in part by CSIR (ESC 0103), DST (GAP 336 and GAP 339), DBT (GAP 346), DBT (GAP 299), and CSIR (BSC 0115, 0113 and 0121). The Director (CSIR-IICB) is kindly acknowledged for providing all institutional facilities. We also thank CRNN-University of Calcutta for providing the HRTEM facility for this study.

\section{ABBREVIATIONS}

SPR, surface plasmon resonance; HRTEM, high-resolution transmission electron microscopy; TPPS, tetrasodium salt of meso-tetrakis(4-sulfonatophenyl)porphyrin; DOX, doxorubicin; AuNPs, gold nanoparticles; DLS, dynamic light scattering

\section{REFERENCES}

(1) Chabner, B. A.; Roberts, T. G. Chemotherapy and the War on Cancer. Nat. Rev. Cancer 2005, 5, 65-72.

(2) Gottesman, M. M.; Fojo, T.; Bates, S. E. Multidrug Resistance in Cancer: Role of ATP-Dependent Transporters. Nat. Rev. Cancer 2002, $2,48-58$.

(3) Ferrari, M. Cancer Nanotechnology: Opportunities and Challenges. Nat. Rev. Cancer 2005, 5, 161-171.

(4) Chithrani, B. D.; Ghazani, A. A.; Chan, W. C. W. Determining the Size and Shape Dependence of Gold Nanoparticle Uptake into Mammalian Cells. Nano Lett. 2006, 6, 662-668.

(5) Lu, W.; Singh, A. K.; Khan, S. A.; Senapati, D.; Yu, H.; Ray, P. C. Gold Nano-Popcorn-Based Targeted Diagnosis, Nanotherapy Treatment, and In Situ Monitoring of Photothermal Therapy Response of Prostate Cancer Cells Using Surface-Enhanced Raman Spectroscopy. J. Am. Chem. Soc. 2010, 132, 18103-18114. 
(6) Mitra, P.; Chakraborty, P. K.; Saha, P.; Ray, P.; Basu, S. Antibacterial Efficacy of Acridine Derivatives Conjugated with Gold Nanoparticles. Int. J. Pharm. 2014, 473, 636-643.

(7) Shan, J.; Tenhu, H. Recent Advances in Polymer Protected Gold Nanoparticles: Synthesis, Properties and Applications. Chem. Commun. 2007, 4580-4598.

(8) Niikura, K.; Iyo, N.; Matsuo, Y.; Mitomo, H.; Ijiro, K. Sub-100 $\mathrm{Nm}$ Gold Nanoparticle Vesicles as a Drug Delivery Carrier Enabling Rapid Drug Release upon Light Irradiation. ACS Appl. Mater. Interfaces 2013, 5, 3900-3907.

(9) Shiao, Y.-S.; Chiu, H.-H.; Wu, P.-H.; Huang, Y.-F. AptamerFunctionalized Gold Nanoparticles As Photoresponsive Nanoplatform for Co-Drug Delivery. ACS Appl. Mater. Interfaces 2014, 6, 2183221841.

(10) Singh, R; Lillard, J. W. Nanoparticle-Based Targeted Drug Delivery. Exp. Mol. Pathol. 2009, 86, 215-223.

(11) Dhamecha, D.; Jalalpure, S.; Jadhav, K.; Jagwani, S.; Chavan, R. Doxorubicin Loaded Gold Nanoparticles: Implication of Passive Targeting on Anticancer Efficacy. Pharmacol. Res. 2016, 113, 547-556.

(12) Chaudhary, A.; Dwivedi, C.; Gupta, A.; Nandi, C. K. One Pot Synthesis of Doxorubicin Loaded Gold Nanoparticles for Sustained Drug Release. RSC Adv. 2015, 5, 97330-97334.

(13) Mirza, A. Z.; Shamshad, H. Preparation and Characterization of Doxorubicin Functionalized Gold Nanoparticles. Eur. J. Med. Chem. 2011, 46, 1857-1860.

(14) Du, Y.; Xia, L.; Jo, A.; Davis, R. M.; Bissel, P.; Ehrich, M. F.; Kingston, D. G. I. Synthesis and Evaluation of Doxorubicin-Loaded Gold Nanoparticles for Tumor-Targeted Drug Delivery. Bioconjugate Chem. 2018, 29, 420-430.

(15) Wang, F.; Wang, Y.-C.; Dou, S.; Xiong, M.-H.; Sun, T.-M.; Wang, J. Doxorubicin-Tethered Responsive Gold Nanoparticles Facilitate Intracellular Drug Delivery for Overcoming Multidrug Resistance in Cancer Cells. ACS Nano 2011, 5, 3679-3692.

(16) Suarasan, S.; Focsan, M.; Potara, M.; Soritau, O.; Florea, A.; Maniu, D.; Astilean, S. Doxorubicin-Incorporated Nanotherapeutic Delivery System Based on Gelatin-Coated Gold Nanoparticles: Formulation, Drug Release, and Multimodal Imaging of Cellular Internalization. ACS Appl. Mater. Interfaces 2016, 8, 22900-22913.

(17) Elbialy, N. S.; Fathy, M. M.; Khalil, W. M. Doxorubicin Loaded Magnetic Gold Nanoparticles for in Vivo Targeted Drug Delivery. Int. J. Pharm. 2015, 490, 190-199.

(18) Lee, C.-S.; Kim, H.; Yu, J.; Yu, S. H.; Ban, S.; Oh, S.; Jeong, D.; Im, J.; Baek, M. J.; Kim, T. H. Doxorubicin-Loaded Oligonucleotide Conjugated Gold Nanoparticles: A Promising in Vivo Drug Delivery System for Colorectal Cancer Therapy. Eur. J. Med. Chem. 2017, 142, 416-423.

(19) Kim, H.; Nguyen, V. P.; Manivasagan, P.; Jung, M. J.; Kim, S. W.; Oh, J.; Kang, H. W.; Kim, H.; Nguyen, V. P.; Manivasagan, P.; et al. Doxorubicin-Fucoidan-Gold Nanoparticles Composite for Dualchemo-Photothermal Treatment on Eye Tumors. Oncotarget 2017, 8, No. 113719.

(20) Ogawa, K.; Kobuke, Y. Two-Photon Photodynamic Therapy by Water-Soluble Self-Assembled Conjugated Porphyrins. BioMed Res. Int. 2013, 2013, 1-11.

(21) Kim, W. J.; Kang, M. S.; Kim, H. K.; Kim, Y.; Chang, T.; Ohulchanskyy, T.; Prasad, P. N.; Lee, K.-S. Water-Soluble PorphyrinPolyethylene Glycol Conjugates with Enhanced Cellular Uptake for Photodynamic Therapy. J. Nanosci. Nanotechnol. 2009, 9, 7130-7135.

(22) Kuimova, M. K.; Collins, H. A.; Balaz, M.; Dahlstedt, E.; Levitt, J. A.; Sergent, N.; Suhling, K.; Drobizhev, M.; Makarov, N. S.; Rebane, A.; et al. Photophysical Properties and Intracellular Imaging of WaterSoluble Porphyrin Dimers for Two-Photon Excited Photodynamic Therapy. Org. Biomol. Chem. 2009, 7, 889-896.

(23) Zou, Q.; Abbas, M.; Zhao, L.; Li, S.; Shen, G.; Yan, X. Biological Photothermal Nanodots Based on Self-Assembly of PeptidePorphyrin Conjugates for Antitumor Therapy. J. Am. Chem. Soc. 2017, 139, 1921-1927.

(24) Ohyama, J.; Hitomi, Y.; Higuchi, Y.; Shinagawa, M.; Mukai, H.; Kodera, M.; Teramura, K.; Shishido, T.; Tanaka, T. One-Phase
Synthesis of Small Gold Nanoparticles Coated by a Horizontal Porphyrin Monolayer. Chem. Commun. 2008, 6300-6302.

(25) Beer, P. D.; Cormode, D. P.; Davis, J. J. Zinc MetalloporphyrinFunctionalised Nanoparticle Anion Sensors. Chem. Commun. 2004, 414-415.

(26) Kanehara, M.; Takahashi, H.; Teranishi, T. Gold(0) Porphyrins on Gold Nanoparticles. Angew. Chem., Int. Ed. 2008, 47, 307-310.

(27) Magno, L. N.; Bezerra, F. C.; Freire, L. E. S.; Guerra, R. A.; Bakuzis, A. F.; Gonçalves, P. J. Use of Spectroscopic Techniques for Evaluating the Coupling of Porphyrins on Biocompatible Nanoparticles. A Potential System for Photodynamics, Theranostics, and Nanodrug Delivery Applications. J. Phys. Chem. A 2017, 121, 19241931.

(28) Conklin, D.; Nanayakkara, S.; Park, T.-H.; Lagadec, M. F.; Stecher, J. T.; Therien, M. J.; Bonnell, D. A. Electronic Transport in Porphyrin Supermolecule-Gold Nanoparticle Assemblies. Nano Lett. 2012, 12, 2414-2419.

(29) Yang, A.; Xue, Y.; Zhao, H.; Li, X.; Yuan, Z. One-Pot Synthesis of Ternary Hybrid Nanomaterial Composed of a Porphyrin-Functionalized Graphene, Tin Oxide, and Gold Nanoparticles, and Its Application to the Simultaneous Determination of Epinephrine and Uric Acid. Microchim. Acta 2015, 182, 341-349.

(30) Trapani, M.; De Luca, G.; Romeo, A.; Castriciano, M. A.; Scolaro, L. M. Spectroscopic Investigation on Porphyrins NanoAssemblies onto Gold Nanorods. Spectrochim. Acta, A. 2017, 173, 343-349.

(31) Boni, L. D.; Franzen, P. L.; Gonçalves, P. J.; Borissevitch, I. E.; Misoguti, L.; Mendonça, C. R.; Zilio, S. C. Pulse Train Fluorescence Technique for Measuring Triplet State Dynamics. Opt. Express 2011, 19, 10813-10823.

(32) Dąbrowski, J. M.; Arnaut, L. G. Photodynamic Therapy (PDT) of Cancer: From Local to Systemic Treatment. Photochem. Photobiol. Sci. 2015, 14, 1765-1780.

(33) Penon, O.; Marín, M. J.; Russell, D. A.; Pérez-García, L. Water Soluble, Multifunctional Antibody-Porphyrin Gold Nanoparticles for Targeted Photodynamic Therapy. J. Colloid Interface Sci. 2017, 496, $100-110$.

(34) Khaing Oo, M. K.; Yang, Y.; Hu, Y.; Gomez, M.; Du, H.; Wang, H. Gold Nanoparticle-Enhanced and Size-Dependent Generation of Reactive Oxygen Species from Protoporphyrin IX. ACS Nano 2012, 6, 1939-1947.

(35) Zhang, L.; Chen, H.; Wang, J.; Li, Y. F.; Wang, J.; Sang, Y.; Xiao, S. J.; Zhan, L.; Huang, C. Z. Tetrakis(4-Sulfonatophenyl)porphyrinDirected Assembly of Gold Nanocrystals: Tailoring the Plasmon Coupling Through Controllable Gap Distances. Small 2010, 6, 20012009.

(36) Düring, J.; Gröhn, F. ZnO Nanorods Assembled with Different Porphyrins - Size-Tunable Hybrid Particles. RSC Adv. 2017, 7, 33213330.

(37) Shaikh, A. J.; Rabbani, F.; Sherazi, T. A.; Iqbal, Z.; Mir, S.; Shahzad, S. A. Binding Strength of Porphyrin-Gold Nanoparticle Hybrids Based on Number and Type of Linker Moieties and a Simple Method To Calculate Inner Filter Effects of Gold Nanoparticles Using Fluorescence Spectroscopy. J. Phys. Chem. A 2015, 119, 1108-1116.

(38) Horiuchi, H.; Kuribara, R.; Hirabara, A.; Okutsu, T. pHResponse Optimization of Amino-Substituted Tetraphenylporphyrin Derivatives as pH-Activatable Photosensitizers. J. Phys. Chem. A 2016, 120, 5554-5561.

(39) Katsonis, N.; Vicario, J.; Kudernac, T.; Visser, J.; Pollard, M. M.; Feringa, B. L. Self-Organized Monolayer of Meso-Tetradodecylporphyrin Coordinated to $\mathrm{Au}(111)$. J. Am. Chem. Soc. 2006, 128, 1553715541.

(40) Maity, M.; Das, S.; Maiti, N. C. Stability and Binding Interaction of Bilirubin on a Gold Nano-Surface: Steady State Fluorescence and FT-IR Investigation. Phys. Chem. Chem. Phys. 2014, 16, 20013-20022.

(41) Maiti, N. C.; Mazumdar, S.; Periasamy, N. J- and H-Aggregates of Porphyrin-Surfactant Complexes: Time-Resolved Fluorescence and Other Spectroscopic Studies. J. Phys. Chem. B 1998, 102, 15281538. 
(42) Borissevitch, I. E.; Parra, G. G.; Zagidullin, V. E.; Lukashev, E. P.; Knox, P. P.; Paschenko, V. Z.; Rubin, A. B. Cooperative Effects in $\mathrm{CdSe} / \mathrm{ZnS}$-PEGOH Quantum Dot Luminescence Quenching by a Water Soluble Porphyrin. J. Lumin. 2013, 134, 83-87.

(43) Kathiravan, A.; Anbazhagan, V.; Jhonsi, M. A.; Renganathan, R. Fluorescence Quenching of Meso-Tetrakis (4-Sulfonatophenyl) Porphyrin by Colloidal $\mathrm{TiO}_{2}$. Spectrochim. Acta, Part A 2008, 70, 615-618.

(44) Kathiravan, A.; Kumar, P. S.; Renganathan, R.; Anandan, S. Photoinduced Electron Transfer Reactions between Meso-tetrakis(4Sulfonatophenyl)porphyrin and Colloidal Metal-Semiconductor Nanoparticles. Colloids Surf., A 2009, 333, 175-181.

(45) Rong, Y.; Chen, P.; Liu, M. Self-Assembly of Water-Soluble TPPS in Organic Solvents: From Nanofibers to Mirror Imaged Chiral Nanorods. Chem. Commun. 2013, 49, 10498-10500.

(46) Zhang, Y.-H.; Chen, D.-M.; He, T.; Liu, F.-C. Raman and Infrared Spectral Study of Meso-Sulfonatophenyl Substituted Porphyrins (TPPSn, n = 1, 2A, 2O, 3, 4). Spectrochim. Acta, Part A 2003, 59, 87-101.

(47) Rahimi, R.; Shokraiyan, J.; Rabbani, M.; Fayyaz, F. Enhanced Photobactericidal Activity of $\mathrm{ZnO}$ Nanorods Modified by Mesotetrakis(4-Sulfonatophenyl)porphyrin under Visible LED Lamp Irradiation. Water Sci. Technol. 2015, 71, 1249-1254.

(48) Perrin, M. L.; Prins, F.; Martin, C. A.; Shaikh, A. J.; Eelkema, R.; van Esch, J. H.; Briza, T.; Kaplanek, R.; Kral, V.; van Ruitenbeek, J. M.; et al. Influence of the Chemical Structure on the Stability and Conductance of Porphyrin Single-Molecule Junctions. Angew. Chem., Int. Ed. 2011, 50, 11223-11226.

(49) Nath, S.; Jana, S.; Pradhan, M.; Pal, T. Ligand-Stabilized Metal Nanoparticles in Organic Solvent. J. Colloid Interface Sci. 2010, 341, 333-352.

(50) Feng, C.; Latimer, E.; Spence, D.; Hindawi, A. M. A. A. A.; Bullen, S.; Boatwright, A.; Ellis, A. M.; Yang, S. Formation of Au and Tetrapyridyl Porphyrin Complexes in Superfluid Helium. Phys. Chem. Chem. Phys. 2015, 17, 16699-16704.

(51) Xu, J.; Yu, H.; Hu, Y.; Chen, M.; Shao, S. A Gold NanoparticleBased Fluorescence Sensor for High Sensitive and Selective Detection of Thiols in Living Cells. Biosens. Bioelectron. 2016, 75, 1-7.

(52) Contino, A.; Maccarrone, G.; Fragalà, M. E.; Spitaleri, L.; Gulino, A. Conjugated Gold-Porphyrin Monolayers Assembled on Inorganic Surfaces. Chem. - Eur. J. 2017, 23, 14937-14943.

(53) Bhaumik, J.; Gogia, G.; Kirar, S.; Vijay, L.; Thakur, N. S.; Banerjee, U. C.; Laha, J. K. Bioinspired Nanophotosensitizers: Synthesis and Characterization of Porphyrin-noble Metal Nanoparticle Conjugates. New J. Chem. 2016, 40, 724-731.

(54) Noda, Y.; Noro, S.; Akutagawa, T.; Nakamura, T. Gold Nanoparticle Assemblies Stabilized by bis(phthalocyaninato)lanthanide(III) Complexes through van Der Waals Interactions. Sci. Rep. 2014, 4, No. 3758.

(55) Evdokimova, M. G.; Konev, A. S.; Povolotckaia, A. V.; Kolesnikov, I. E.; Kazakova, A. V.; Povolotskiy, A. V. Determining the Mechanism of Interaction between Molecules of Porphyrin and Fullerene and Gold Nanoparticles, Based on Luminescence Spectroscopy Data. Bull. Russ. Acad. Sci. Phys. 2017, 81, 1391-1395.

(56) Tanaka, D.; Inuta, Y.; Sakamoto, M.; Furube, A.; Haruta, M.; So, Y.-G.; Kimoto, K.; Hamada, I.; Teranishi, Т. Strongest $\Pi-$ metal Orbital Coupling in a Porphyrin/gold Cluster System. Chem. Sci. 2014, 5, 2007-2010.

(57) Carbone, M. Bi-Verse Relationship between Gold Nanoparticles and Intracellular pH. J. King Saud Univ., Sci. 2017, 29, 284-290.

(58) Yang, X.; Zhang, X.; Liu, Z.; Ma, Y.; Huang, Y.; Chen, Y. HighEfficiency Loading and Controlled Release of Doxorubicin Hydrochloride on Graphene Oxide. J. Phys. Chem. C 2008, 112, 1755417558.

(59) Mahdavi, M.; Rahmani, F.; Nouranian, S. Molecular Simulation of pH-Dependent Diffusion, Loading, and Release of Doxorubicin in Graphene and Graphene Oxide Drug Delivery Systems. J. Mater. Chem. B 2016, 4, 7441-7451.
(60) Hanyż, I.; Wróbel, D. The Influence of $\mathrm{pH}$ on Charged Porphyrins Studied by Fluorescence and Photoacoustic Spectroscopy. Photochem. Photobiol. Sci. 2002, 1, 126-132.

(61) Gottesman, M. M.; Pastan, I.; Ambudkar, S. V. P-Glycoprotein and Multidrug Resistance. Curr. Opin. Genet. Dev. 1996, 6, 610-617.

(62) Szakács, G.; Paterson, J. K.; Ludwig, J. A.; Booth-Genthe, C.; Gottesman, M. M. Targeting Multidrug Resistance in Cancer. Nat. Rev. Drug Discov. 2006, 5, 219-234.

(63) Liscovitch, M.; Lavie, Y. Cancer Multidrug Resistance: A Review of Recent Drug Discovery Research. IDrugs 2002, 5, 349-355.

(64) Bähr, O.; Rieger, J.; Duffner, F.; Meyermann, R.; Weller, M.; Wick, W. P-Glycoprotein and Multidrug Resistance-Associated Protein Mediate Specific Patterns of Multidrug Resistance in Malignant Glioma Cell Lines, but Not in Primary Glioma Cells. Brain Pathol. 2003, 13, 482-494.

(65) Raoof, M.; Corr, S. J.; Kaluarachchi, W. D.; Massey, K. L.; Briggs, K.; Zhu, C.; Cheney, M. A.; Wilson, L. J.; Curley, S. A. Stability of Antibody-Conjugated Gold Nanoparticles in the Endo-Lysosomal Nanoenvironment: Implications for Non-Invasive RadiofrequencyBased Cancer Therapy. Nanomed. Nanotechnol. Biol. Med. 2012, 8, $1096-1105$.

(66) Kumar, A.; Ma, H.; Zhang, X.; Huang, K.; Jin, S.; Liu, J.; Wei, T.; Cao, W.; Zou, G.; Liang, X.-J. Gold Nanoparticles Functionalized with Therapeutic and Targeted Peptides for Cancer Treatment. Biomaterials 2012, 33, 1180-1189.

(67) Pan, Y.; Neuss, S.; Leifert, A.; Fischler, M.; Wen, F.; Simon, U.; Schmid, G.; Brandau, W.; Jahnen-Dechent, W. Size-Dependent Cytotoxicity of Gold Nanoparticles. Small 2007, 3, 1941-1949.

(68) Vijayakumar, S.; Ganesan, S. In Vitro Cytotoxicity Assay on Gold Nanoparticles with Different Stabilizing Agents. J. Nanomater. 2012, 2012, 1-9.

(69) Vijayakumar, S.; Ganesan, S. Size-Dependent in Vitro Cytotoxicity Assay of Gold Nanoparticles. Toxicol. Environ. Chem. 2013, 95, 277-287.

(70) Wang, R.-H.; Bai, J.; Deng, J.; Fang, C.-J.; Chen, X. TATModified Gold Nanoparticle Carrier with Enhanced Anticancer Activity and Size Effect on Overcoming Multidrug Resistance. ACS Appl. Mater. Interfaces 2017, 9 (7), 5828-5837.

(71) Coradeghini, R.; Gioria, S.; García, C. P.; Nativo, P.; Franchini, F.; Gilliland, D.; Ponti, J.; Rossi, F. Size-Dependent Toxicity and Cell Interaction Mechanisms of Gold Nanoparticles on Mouse Fibroblasts. Toxicol. Lett. 2013, 217, 205-216.

(72) Chhour, P.; Kim, J.; Benardo, B.; Tovar, A.; Mian, S.; Litt, H. I.; Ferrari, V. A.; Cormode, D. P. Effect of Gold Nanoparticle Size and Coating on Labeling Monocytes for CT Tracking. Bioconjugate Chem. 2017, 28, 260-269.

(73) Huo, S.; Jin, S.; Ma, X.; Xue, X.; Yang, K.; Kumar, A.; Wang, P. C.; Zhang, J.; Hu, Z.; Liang, X.-J. Ultrasmall Gold Nanoparticles as Carriers for Nucleus-Based Gene Therapy Due to Size-Dependent Nuclear Entry. ACS Nano 2014, 8, 5852-5862.

(74) Yohan, D.; Cruje, C.; Lu, X.; Chithrani, D. B. Size-Dependent Gold Nanoparticle Interaction at Nano-Micro Interface Using Both Monolayer and Multilayer (Tissue-Like) Cell Models. Nano-Micro Lett. 2016, 8, 44-53.

(75) Boyoglu, C.; He, Q.; Willing, G.; Boyoglu-Barnum, S.; Dennis, V. A.; Pillai, S.; Singh, S. R. Microscopic Studies of Various Sizes of Gold Nanoparticles and Their Cellular Localizations. ISRN Nanotechnol. 2013, 2013, 1-13.

(76) Pissuwan, D.; Niidome, T.; Cortie, M. B. The Forthcoming Applications of Gold Nanoparticles in Drug and Gene Delivery Systems. J. Controlled Release 2011, 149, 65-71.

(77) Simpson, C. A.; Huffman, B. J.; Gerdon, A. E.; Cliffel, D. E. Unexpected Toxicity of Monolayer Protected Gold Clusters Eliminated by PEG-Thiol Place Exchange Reactions. Chem. Res. Toxicol. 2010, 23, 1608-1616.

(78) Alkilany, A. M.; Murphy, C. J. Toxicity and Cellular Uptake of Gold Nanoparticles: What We Have Learned so Far? J. Nanopart. Res. 2010, 12, 2313-2333. 
(79) Doherty, G. J.; McMahon, H. T. Mechanisms of Endocytosis. Annu. Rev. Biochem. 2009, 78, 857-902.

(80) Dasary, S. S. R.; Singh, A. K.; Senapati, D.; Yu, H.; Ray, P. C. Gold Nanoparticle Based Label-Free SERS Probe for Ultrasensitive and Selective Detection of Trinitrotoluene. J. Am. Chem. Soc. 2009, 131, 13806-13812.

(81) Jain, S.; Webster, T. J.; Sharma, A.; Basu, B. Intracellular Reactive Oxidative Stress, Cell Proliferation and Apoptosis of Schwann Cells on Carbon Nanofibrous Substrates. Biomaterials 2013, 34, 4891-4901.

(82) Dasgupta, P.; Bhattacharya, A.; Pal, R.; Dasgupta, A. K.; Bandyopadhayay, S. S. Synthesis of Diallyl Disulfide (DADS) Induced Gold Nanoparticles: Characterization and Study of Its Biological Activity in Human Leukemic Cell-Lines. RSC Adv. 2015, 5, 1842918437.

(83) Zhang, Q.; Large, N.; Wang, H. Gold Nanoparticles with Tipped Surface Structures as Substrates for Single-Particle SurfaceEnhanced Raman Spectroscopy: Concave Nanocubes, Nanotrisoctahedra, and Nanostars. ACS Appl. Mater. Interfaces 2014, 6, 1725517267.

(84) Huang, Y.; Dai, L.; Song, L.; Zhang, L.; Rong, Y.; Zhang, J.; Nie, Z.; Chen, T. Engineering Gold Nanoparticles in Compass Shape with Broadly Tunable Plasmon Resonances and High-Performance SERS. ACS Appl. Mater. Interfaces 2016, 8, 27949-27955.

(85) Ma, N.; Wu, F.-G.; Zhang, X.; Jiang, Y.-W.; Jia, H.-R.; Wang, H.Y.; Li, Y.-H.; Liu, P.; Gu, N.; Chen, Z. Shape-Dependent Radiosensitization Effect of Gold Nanostructures in Cancer Radiotherapy: Comparison of Gold Nanoparticles, Nanospikes, and Nanorods. ACS Appl. Mater. Interfaces 2017, 9, 13037-13048.

(86) Xue, C.; Birel, O.; Li, Y.; Ma, X.; Gao, M.; Urbas, A.; Li, Q. Porphyrin Metal Complex Monolayer-Protected Gold Nanorods: A Parallel Facile Synthesis and Self-Assembly. J. Colloid Interface Sci. 2013, 398, 1-6.

(87) Canitez, F. K.; Yavuz, M. S.; Ozturk, R. One-Pot Synthesis of Gold Nanoparticles Using Tetradentate Porphyrins. J. Nanopart. Res. 2011, 13, 7219-7228.

(88) Papadimitriou, S.; Bikiaris, D. Novel Self-Assembled Core-Shell Nanoparticles Based on Crystalline Amorphous Moieties of Aliphatic Copolyesters for Efficient Controlled Drug Release. J. Controlled Release 2009, 138, 177-184.

(89) Pandey, S.; Oza, G.; Mewada, A.; Shah, R.; Thakur, M.; Sharon, M. Folic Acid Mediated Synaphic Delivery of Doxorubicin Using Biogenic Gold Nanoparticles Anchored to Biological Linkers. J. Mater. Chem. B 2013, 1, 1361-1370.

(90) Bhattacharya, K.; Bag, A. K.; Tripathi, R.; Samanta, S. K.; Pal, B. C.; Shaha, C.; Mandal, C. Mahanine, a Novel Mitochondrial ComplexIII Inhibitor Induces G0/G1 Arrest through Redox AlterationMediated DNA Damage Response and Regresses Glioblastoma Multiforme. Am. J. Cancer Res. 2014, 4, 629-647.

(91) Das, R.; Bhattacharya, K.; Samanta, S. K.; Pal, B. C.; Mandal, C. Improved Chemosensitivity in Cervical Cancer to Cisplatin: Synergistic Activity of Mahanine through STAT3 Inhibition. Cancer Lett. 2014, 351, 81-90.

(92) Sarkar, S.; Mandal, C.; Sangwan, R.; Mandal, C. Coupling G2/ $\mathrm{M}$ Arrest to the Wnt/ $\beta$-Catenin Pathway Restrains Pancreatic Adenocarcinoma. Endocr.-Relat. Cancer 2014, 21, 113-125.

(93) Bhattacharya, K.; Chandra, S.; Mandal, C. Critical Stoichiometric Ratio of CD4+ CD25+ FoxP3+ Regulatory T Cells and CD4+ CD25- Responder T Cells Influence Immunosuppression in Patients with B-Cell Acute Lymphoblastic Leukaemia. Immunology 2014, 142, 124-139.

(94) Bhattacharya, K.; Samanta, S. K.; Tripathi, R.; Mallick, A.; Chandra, S.; Pal, B. C.; Shaha, C.; Mandal, C. Apoptotic Effects of Mahanine on Human Leukemic Cells Are Mediated through Crosstalk between Apo-1/Fas Signaling and the Bid Protein and via Mitochondrial Pathways. Biochem. Pharmacol. 2010, 79, 361-372.

(95) Das, R.; Bhattacharya, K.; Sarkar, S.; Samanta, S. K.; Pal, B. C.; Mandal, C. Mahanine Synergistically Enhances Cytotoxicity of 5-
Fluorouracil through ROS-Mediated Activation of PTEN and p53/p73 in Colon Carcinoma. Apoptosis 2014, 19, 149-164.

(96) Bhattacharya, K.; Maiti, S.; Mandal, C. PTEN Negatively Regulates mTORC2 Formation and Signaling in Grade IV Glioma via Rictor Hyperphosphorylation at Thr1135 and Direct the Mode of Action of an mTORC1/2 Inhibitor. Oncogenesis 2016, 5, No. e227.

(97) Sarkar, S.; Dutta, D.; Samanta, S. K.; Bhattacharya, K.; Pal, B. C.; Li, J.; Datta, K.; Mandal, C.; Mandal, C. Oxidative Inhibition of Hsp90 Disrupts the Super-Chaperone Complex and Attenuates Pancreatic Adenocarcinoma in Vitro and in Vivo. Int. J. Cancer 2013, 132, 695706

(98) Mandal, C.; Dutta, A.; Mallick, A.; Chandra, S.; Misra, L.; Sangwan, R. S.; Mandal, C. Withaferin A Induces Apoptosis by Activating p38 Mitogen-Activated Protein Kinase Signaling Cascade in Leukemic Cells of Lymphoid and Myeloid Origin through Mitochondrial Death Cascade. Apoptosis 2008, 13, 1450-1464.

(99) Mandal, C.; Tringali, C.; Mondal, S.; Anastasia, L.; Chandra, S.; Venerando, B.; Mandal, C. Down Regulation of Membrane-Bound Neu3 Constitutes a New Potential Marker for Childhood Acute Lymphoblastic Leukemia and Induces Apoptosis Suppression of Neoplastic Cells. Int. J. Cancer 2010, 126, 337-349.

(100) Maiti, S.; Mondal, S.; Satyavarapu, E. M.; Mandal, C. mTORC2 Regulates Hedgehog Pathway Activity by Promoting Stability to Gli2 Protein and Its Nuclear Translocation. Cell Death Dis. 2017, 8, No. e2926.

(101) Mandal, C.; Sarkar, S.; Chatterjee, U.; Schwartz-Albiez, R.; Mandal, C. Disialoganglioside GD3-Synthase over Expression Inhibits Survival and Angiogenesis of Pancreatic Cancer Cells through Cell Cycle Arrest at S-Phase and Disruption of Integrin- $\beta 1$-Mediated Anchorage. Int. J. Biochem. Cell Biol. 2014, 53, 162-173.

(102) Rejman, J.; Bragonzi, A.; Conese, M. Role of Clathrin- and Caveolae-Mediated Endocytosis in Gene Transfer Mediated by Lipoand Polyplexes. Mol. Ther. 2005, 12, 468-474.

(103) Fielding, A. B.; Willox, A. K.; Okeke, E.; Royle, S. J. ClathrinMediated Endocytosis Is Inhibited during Mitosis. Proc. Natl. Acad. Sci. U.S.A. 2012, 109, 6572-6577.

(104) Kam, N. W. S.; Liu, Z.; Dai, H. Carbon Nanotubes as Intracellular Transporters for Proteins and DNA: An Investigation of the Uptake Mechanism and Pathway. Angew. Chem., Int. Ed. 2006, 45, 577-581. 